\title{
Analysis of rock cutting process with a blunt PDC cutter under different wear flat inclination angles
}

\author{
Iman Rostamsowlat ${ }^{\mathrm{a}, *}$, Babak Akbari ${ }^{\mathrm{b}}$, Brian Evans $^{\mathrm{c}}$ \\ ${ }^{a}$ Deep Exploration Technologies CRC, Department of Petroleum Engineering, Curtin \\ University, Kensington, WA 6151, Australia \\ ${ }^{b}$ Craft and Hawkins Department of Petroleum Engineering, Louisiana State University, Old \\ Forestry Building \#125, Baton Rouge, LA 70803, USA \\ ${ }^{c}$ Department of Petroleum Engineering, Curtin University, Australia
}

\begin{abstract}
It is generally accepted that drilling with drag bits (Polycrystalline Diamond Compact bits) simultaneously consists of "pure cutting" and "frictional contact" processes. To date, the mechanics of rock cutting have been mostly based on the assumption that these two processes are fully independent as the influence of wear flat inclination angle $(\beta)$ with respect to the cutter velocity vector $(\boldsymbol{v})$ on the frictional contact force is often not accounted for. The specific aim of this study is to determine the effect of wear flat inclination angle on the frictional force acting on the wear flat surface of a single blunt cutter over a wide range of depths of cut $(d)$. For this purpose, an extensive and comprehensive set of cutting experiments was performed on two sedimentary rock samples (a limestone and a sandstone) using a state-of-the-art rock cutting equipment and a unique cutter holder. The results show that the normal contact stress $(\sigma)$ at the wear flat-rock interface (and therefore the normal frictional force acting on the wear flat) is dependent on the depth of cut within the elastoplastic and particularly plastic regimes of frictional contact; however, the contact stress is invariant with depth of cut within the elastic regime. Further investigations indicate that the assumption that the force acting on the wear flat surface of
\end{abstract}

\footnotetext{
${ }^{*}$ Corresponding author:

Email address: iman.rostamsowlat@postgrad.curtin.edu.au, iman.rostamsowlat@gmail.com (Iman Rostamsowlat)
}

Preprint submitted to Journal of Petroleum Science and Engineering

May 24, 2018 
a blunt cutter is independent of the cutting process taking place ahead of the cutter is not valid in particular, for the large values of inclination angles.

Keywords: Rock cutting, Contact stress, Wear flat inclination angle, Depth of cut, Pure cutting process, Frictional contact process

\section{List of symbols}

\begin{tabular}{ll}
$F$ & Total force acting on the cutter \\
$F_{c}, F_{f}$ & Total cutting and frictional contact forces \\
$F_{c n}, F_{c s}$ & Normal and tangential components of the total cutting force \\
$F_{f n}, F_{f s}$ & Normal and tangential components of the total frictional contact force \\
$\tilde{F_{f n}}, \tilde{F_{f s}}$ & Projected components of the contact force components \\
$d$ & Depth of cut \\
$A_{c}$ & Cross-sectional area of groove traced by cutter \\
$A_{f}$ & Wear flat area \\
$\omega$ & Width of cutter \\
$q$ & Uniaxial compressive strength of the rock material \\
$\zeta$ & Ratio of normal component to tangential component of cutting force \\
$\varepsilon$ & Intrinsic specific energy \\
$\theta$ & Back rake angle \\
$\theta_{*}$ & Initial back rake angle \\
$\Delta \theta_{*}$ & Relative increment of back rake angle \\
$\psi$ & Interfacial friction angle \\
$v$ & Horizontal cutting tool velocity \\
$\mu$ & Friction coefficient \\
$\sigma$ & Normal contact stress \\
$\ell$ & Length of wear flat surface \\
$\beta$ & Inclination angle of wear flat with respect to velocity vector \\
$E^{*}$ & Plane strain elastic modulus of the rock sample \\
$\prod$ & Scaled contact stress \\
$\eta$ & Dimensionless number \\
\hline &
\end{tabular}


$\chi \quad$ Chamfer angle

$\Delta z \quad$ Relative vertical displacement of spindle

\section{Introduction}

Better understanding of rock cutting or fragmenting has been one of the main objectives of drilling research since the 1950s and has received increased attention in both theoretical and experimental research areas. Drilling has been 5 performed mainly using roller cone bits, until the introduction of PDC (Polycrystalline Diamond Compact) drag bits in the late 1970's [1-4]. The application of this new material reduced the drilling costs by improving the efficiency (their high rate of penetration ROP) and the lifetime of the bits. Due to the shear cutting mechanism of the PDC drill bits, they drill several times faster than roller cone bits [5, 6]. A PDC bit consists of a matrix (tungsten carbide metallurgically bonded with a metallic binder) or steel body that is covered with inserts often referred to as PDC cutters which are made of a thin layer of synthetic polycrystalline diamond bonded on a tungsten carbide substrate. A PDC drag bit is actually composed of a multiplicity of individual PDC cutters mounted at the surface of a bit body. Therefore, a study of the drilling response of PDC bits can be done by establishing the cutting response of an individual cutter [7-11].

It is commonly admitted in the literature [12 17, that the cutting action of a blunt (worn) cutter or drag bit can be divided into two independent processes: (i) a pure cutting action in front of the cutting face, and (ii) a frictional process mobilized across the wear flat surface. To date, a large body of research studies (both numerical simulations and experimental investigations) have been mainly based on this main assumption that these two processes (pure cutting and frictional contact) are uncoupled. In other words, the total force acting

25 on a single blunt cutter or drag bit can be simply written as the sum of two independent forces, $\mathbf{F}_{\mathbf{c}}$ and $\mathbf{F}_{\mathbf{f}}$ which coexist and are associated with the pure cutting (subscript $c$ ) and frictional contact processes (subscript $f$ ), respectively 
(Eq. 1).

$$
\mathbf{F}=\mathbf{F}_{\mathbf{c}}+\mathbf{F}_{\mathbf{f}}
$$

On the other hand, in the overwhelming majority of research studies on

30 (or eventually the normal contact stress $(\sigma)$ mobilized across the wear flat-rock interface) is independent of both the inclination angle $\beta$ (defined as the angle between the wear flat surface and the linear velocity vector of the cutter $\boldsymbol{v}$ ) and the rate of penetration ROP (defined as the depth of cur per revolution 35 which is equivalent to the depth of cut $(d)$ for a single cutter [18]), see Fig. 1. Little research [19 22] has been reported, however, on the predominant influence of the inclination angle $(\beta)$ on the normal contact stress at wear flatrock interface. Nonetheless, to the best knowledge of the authors, no reliable and robust study has been devoted to review the validation of the independence a consideration of the variations of wear flat inclination angle $(\beta)$ at different cutting depths $(d)$.

The main objective of this paper is to investigate experimentally, how the inclination angle affects the normal contact stress at the wear flat-rock interface ferent depths of cut (or ROP). In addition, the main assumption of the bit-rock interaction model, indicating the independence between the cutting and friction processes, is also reviewed and discussed with consideration of the inclination angle. To this end, an extensive campaign of cutting tests equivalent to the excavation process (but under dry conditions) with different wear flat inclination angles $(\beta)$, different depths of cut $(d)$, and two rock materials was conducted using a state-of-the-art scratching device (Wombat) and a novel cutter holder allowing for precise adjustment of the angle of inclination $(\beta)$ by steps of $0.10^{\circ}$. 


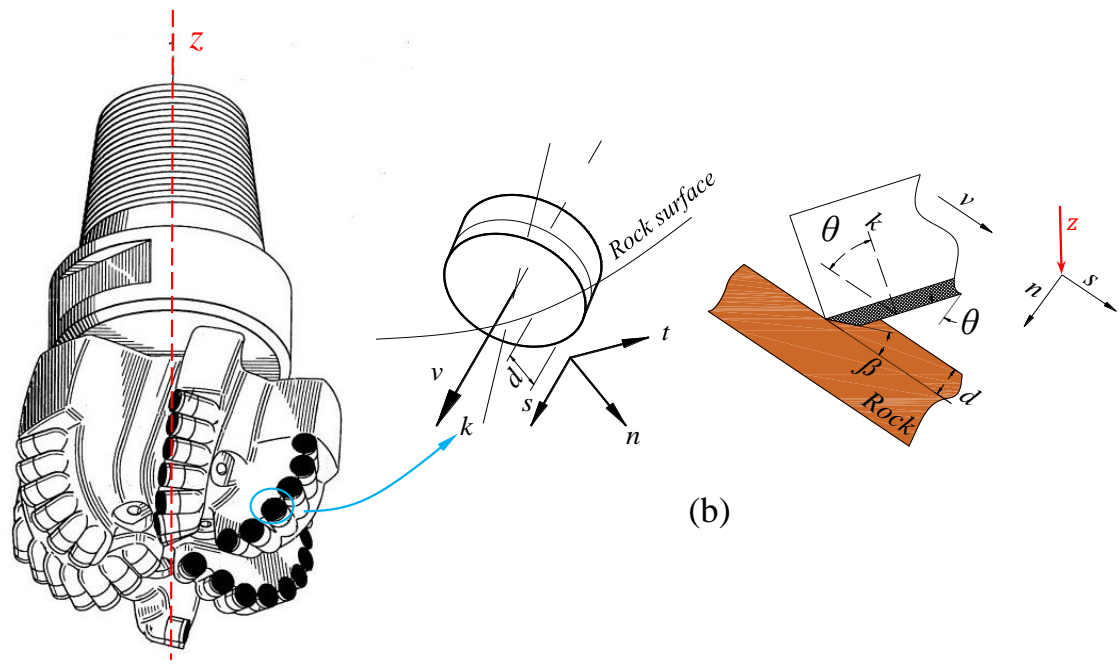

(a)

Figure 1: (a) 3D drawing of a PDC bit (updated from [23]), and (b) sketches of a worn cutter tracing a groove of depth $d$ on the bottom hole. The angle $\beta$ is the angle between the cutter wear surface and the cutter linear velocity $(v)$.

In this paper, we first review the models of rock cutting, with consideration given to the ductile mode of failure [24]. Then, the phenomenological model of rock cutting [14] commonly used in rock cutting, is derived. We then describe the experimental setup, equipment specifications, and the physical properties of the rock materials used in this study. Finally, we provide compelling evidence that the frictional force is a function of depth of cut and that the "pure cutting" and "frictional contact" processes are not fully two independent processes.

\section{Models of cutting process with a single cutter}

Rock cutting or rock scratching can be described as the shaving or machining of a layer of rock from a free surface with the tool moving parallel to the free surface. The first cutting models were inspired from the metal cutting model presented by Merchant in 1944 [25, 26]. Merchant's semi-empirical model was 
based on a Mohr-Coulomb plasticity criterion and force equilibrium of a single shear plane in orthogonal cutting action. The application of Merchant's model was limited to rock cutting as it was based on the assumption of a perfectly sharp cutter while, in practice, the cutters develop a wear flat which affects the force on the cutter. Subsequently, other authors [27H31] have proposed the Merchant based models.

Nishimatsu [29] was one of the first to offer a model suitable for cutting rocks. His study has inspired other researchers to develop models based on different concepts of mechanical destruction of the rock. Nishimatsu's model was more applicable for chip formations and discontinuous rock cutting but this model fails for the ductile mode of failure. Another limitation of Nishimatsu's model was that the effect of wear flat was not accounted for [17, 29, 32, 33].

Lebrun [30], extending Nishimatsu's theory, developed a three dimensional model for the failure of the rock subjected to the action of a cutting tool. Lebrun proposed that the cutting force and the depth of cut are linearly related, with a coefficient of proportionality that depends on the width, wear and rake angle of the cutter. He also stated that the cutting and normal forces are linearly related, with a proportionality coefficient that depends mainly on the degree of wear. Cheatham [34] has shown that the cutter forces are functions of cutting area and rock shear strength. This researcher has also shown that the cutter forces are independent of the particular cutter shape and can be predicted with Merchant's metal cutting model.

The limitation of many models available in the literature is that the effect of wear flat is often not accounted for. Therefore, a model of rock cutting was then developed by Glowka 13,32 while the frictional contact between the cutter and free surface of the rock was taken into account. He analyzed the effect of temperature on wear and also studied the effect of wear on the efficiency of the cutting tool.

A phenomenological model proposed by Detournay \& Defourny [14] (referred 95 to as the "DD-model") was based on the suggestion of Fairhurst and Lacabanne [16] that the force acting on a single cutter is governed by the coexistence of 
two independent processes: the "pure cutting" process in front of the cutting face and the "frictional contact" mobilized across the wear flat surface. This model was validated against experimental results published by Glowka (1987) and developed to describe the rock cutting process under conditions when the mode of rock failure induced by the cutter can be described as plastic. This is typically the failure mode (ductile mode of failure) observed in sedimentary rocks at shallow depth of cut (typically less than $1 \mathrm{~mm}$ ) [14, 24, 35, 38. Since then, Almenara (1992), Samiselo(1992), Lasserre (1994) and Adachi (1996) also provided experimental support to the DD-model.

The DD-model is mainly based on the following assumptions:

1. the cutting process can be decomposed into two independent processes: the "pure cutting" process and the "frictional contact" at the wear flatrock interface,

2. the force acting on the cutting face is proportional to the cross-sectional area of the groove $\left(A_{c}\right)$, and

3. the total force (frictional force) acting on the wear flat-rock interface of a blunt cutter is independent from the depth of cut $(d)$ and its normal and tangential components are related by a frictional law.

115

As mentioned in the section 2, Detournay and Defourny (1992) proposed a phenomenological model (DD-model) for the forces acting on a single cutter and/or PDC drag bit which were compared to the experimental data. The model dealt with the pure cutting (sharp cutter) and the frictional contact depth of cut 35] and the main focus of the DD-model is only on the ductile mode of the failure taking place at the shallow depths of cut [24, 35]. 
First, a perfectly sharp cutter is considered in Fig. 22. According to the cutter tip, the total force acting on the cutter represents only the cutting force $\left(\mathbf{F}=\mathbf{F}_{\mathbf{c}}\right)$ 8. In other words, the force acting on the cutting face is only utilized in cutting rocks. The cutter traces a groove at a constant depth of cut $(d)$ and moves in a horizontal direction, as depicted by the velocity vector $(\boldsymbol{v})$.

Therefore, instead of considering peak forces, the model takes into account the forces "averaged over a distance, large compared to the depth of cut" 24]. Considering the second assumption of the DD-model in section 2, the total cutting force $\left(\mathbf{F}_{\mathbf{c}}\right)$ can be decomposed into components; normal $\left(\mathbf{F}_{\mathbf{c n}}\right)$ and tangential ${ }_{135}\left(\mathbf{F}_{\mathbf{c s}}\right)$ to the rock surface and can be written as:

$$
\left\{\begin{array}{c}
F_{c n}=\zeta \varepsilon A_{c} \\
F_{c s}=\varepsilon A_{c}
\end{array}\right.
$$

where $\varepsilon$ is the intrinsic specific energy (minimum energy to remove a unit volume of the rock with the dimension of stress $M P a$ 43]) that is found well correlated with the uniaxial compressive strength of the rock $(q)$ [24, 44, 47, $A_{c}$ is the cross-sectional area of the groove traced by the cutter (which for a rectangular shaped cutter, is equal to cutter width $(\omega)$ multiplied by the depth of cut $(d))$ and the number $\zeta\left(\zeta=\tan (\theta+\psi)=\frac{F_{c n}}{F_{c s}}\right)$ can be simply interpreted as the ratio of normal to tangential components of the cutting force. Here, $\psi$ is the interfacial friction angle and $\theta$ is the back rake angle (positive when inclined forward) which is defined as the angle between the normal to the cutting face ${ }_{145}(k)$ and the velocity vector $(\boldsymbol{v})$. 


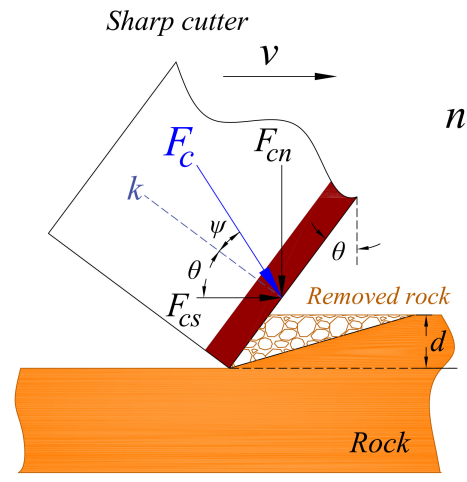

(a)

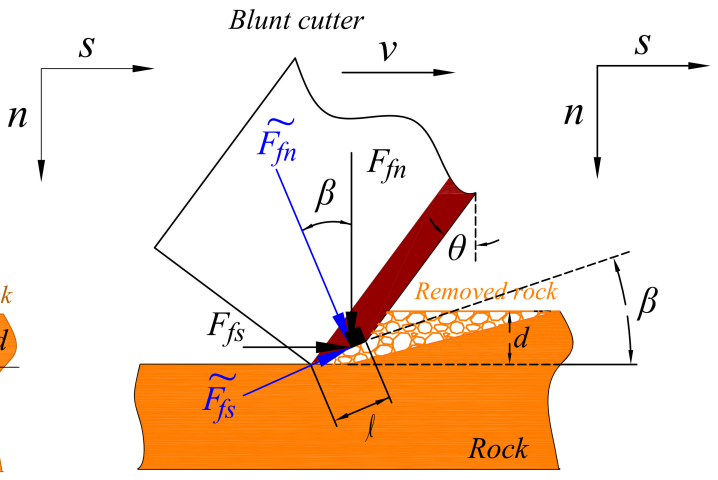

(b)

Figure 2: Forces acting on (a) a sharp PDC cutter, and (b) a blunt PDC cutter.

When a sharp cutter wears, the cutter turns blunt and a wear flat emerges. This wear flat is in contact with the rock and therefore transmits an additional force, next to the cutting force, which is utilized in overcoming friction at the wear flat-rock interface, see Fig. 2p. Under the wear flat, the normal and tangential components of the total frictional force $\left(\mathbf{F}_{\mathbf{f}}\right)$ are constrained by the following friction law:

$$
\mu(d)=\frac{\tilde{F_{f s}}}{\tilde{F_{f n}}}
$$

where $\mu$ is the friction coefficient mobilized at the interface, $\tilde{F_{f n}}$ and $\tilde{F_{f s}}$ are, respectively, the frictional force components projected on the normal and tangent to the wear flat surface with precise consideration of the inclination angle of the wear flat surface $(\beta)$. These force components are given as:

$$
\left\{\begin{array}{l}
\tilde{F_{f n}}=F_{f n} \cos \beta+F_{f s} \quad \sin \beta \\
\tilde{F_{f s}}=F_{f s} \cos \beta-F_{f n} \sin \beta
\end{array}\right.
$$

where on account of Eq. 1 the frictional force components can be readily 
obtained by:

$$
\left\{\begin{array}{l}
F_{f s}(d, \theta)=F_{s}(d, \theta)-F_{c s}(d, \theta) \\
F_{f n}(d, \theta)=F_{n}(d, \theta)-F_{c n}(d, \theta)
\end{array}\right.
$$

and $F_{f}(d, \theta)$ is the force measured on a blunt cutter at a given depth of cut $(d)$ and at a given back rake angle $(\theta)$, and $F_{c}(d, \theta)$ is the force measured on a sharp cutter for the same depth of cut and back rake angle. It is important to reiterate that the normal $F_{c n}(d, \theta)$ and tangential $F_{c s}(d, \theta)$ components of the pure cutting force are measured from tests performed with a sharp cutter [48].

In addition, the normal contact stress mobilized at the wear flat-rock interface reads as:

$$
\sigma(d)=\frac{F_{f n} \cos \beta+F_{f s} \sin \beta}{\omega \ell}=\frac{\tilde{F_{f n}}}{\tilde{A_{f}}}
$$

where $\sigma$ is the contact stress mobilized across the wear flat (which is of the order of the uniaxial compressive strength $q$ [21, 39, 41, 42, 49, 51]) and $A_{f}$ is the wear flat area $\left(A_{f}=\omega \times \ell\right.$ for a rectangular shaped cutter with $\ell$ being the length of wear flat surface, see Fig. 2p).

Experimental results reveal three distinct phases in the cutting response of a worn cutter (or drilling response of a drag bit) with respect to the depth of cut $(d)$ [19, 49 52, see Fig. 3. At shallow depth of cut (phase I), it is assumed that the two contacting surfaces (the cutter wear flat and the rock surfaces) are not entirely conforming, and increase in depth of cut leads to an increase in both the cutting force associated with the pure cutting process but also in 175 the effective contact area $\left(A_{f}\right)$, up to a critical depth of cut $\left(d<d_{*}\right)$. In phase II $\left(d_{*} \leq d \leq d_{* *}\right)$, the effective contact area has reached a limit value $\left(A_{f}=A_{f *}\right)$, and the incremental drilling-cutting response is governed by the pure cutting process [51. On a drill bit, phase III is marked by the occurrence of an additional contact between the rock and bit body as an excess of cuttings is not efficiently flushed away from the bit face. 


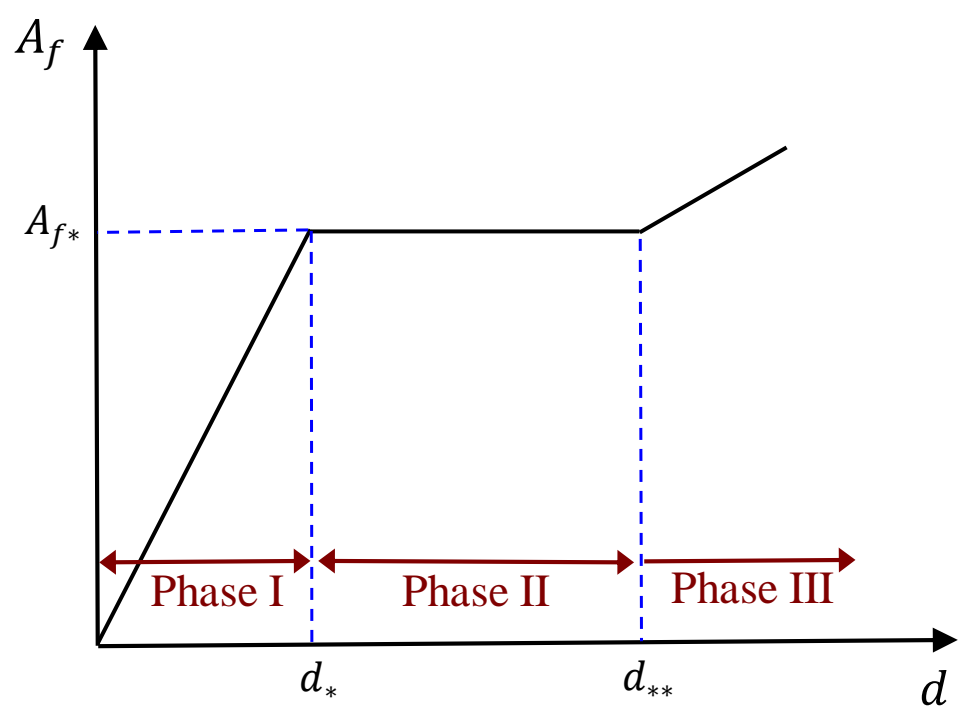

Figure 3: Conceptual Evolution of contact area $\left(A_{f}\right)$ with depth of cut $(d)$ for a blunt cutter.

The response of a blunt cutter in a force-depth of cut relationship is illustrated in Fig. 4. The extent of phase I is controlled by the size of the wear surface and the angle $\beta$ [21]; in phase II, the response is parallel to the response of a sharp cutter [14, 39, 42, 50]. 


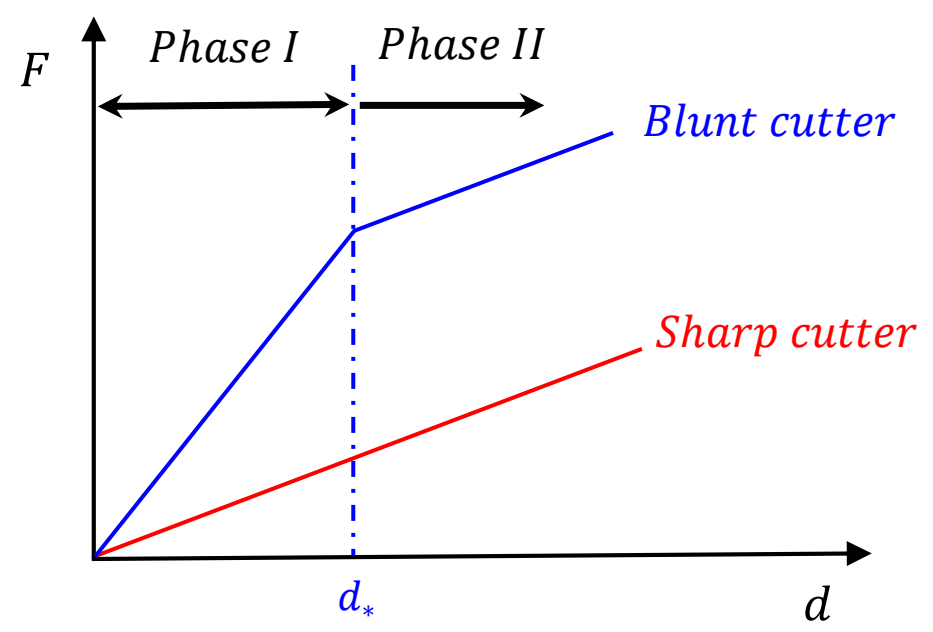

Figure 4: Conceptual plot of force against depth of cut for both a sharp and blunt cutters.

Furthermore, numerical [20] and experimental studies [21, 22, 48, with a single blunt PDC cutter consistently indicate that the scaled contact stress $\left(\Pi=\frac{\sigma}{q}\right)$ at the wear flat-rock interface is predominantly controlled by one dimensionless number $\eta=\frac{E^{*} \tan \beta}{q}$ where $E^{*}$ is the plane strain elastic modulus of the rock sample. As a consequence, three regimes of frictional contact exist (identified as elastic, elastoplastic and fully plastic) depending on the value of $\beta$ (or eventually the dimensionless number $\eta$ ), see Fig. 5. More recently, 21, 22, a comprehensive set of cutting experiments was carried out on Tuffeau limestone and Mountain Gold sandstone using a single blunt PDC cutter to confirm the existence and location of these three regimes of frictional contact. Experimental observations show that the elastic $\left(\beta_{e}\right)$ and plastic $\left(\beta_{p}\right)$ limits sit at about the same angle for both rock samples $\left(\beta_{e} \simeq 2.40^{\circ}\right.$ and $\left.\beta_{p} \simeq 7.40^{\circ}\right)$, as shown in Fig. 5 . This dependency of the contact stress on the angle $\beta$ should be accounted for when modeling the dynamic response (torsional or axial vibrations) of PDC drill bits 5362 . 


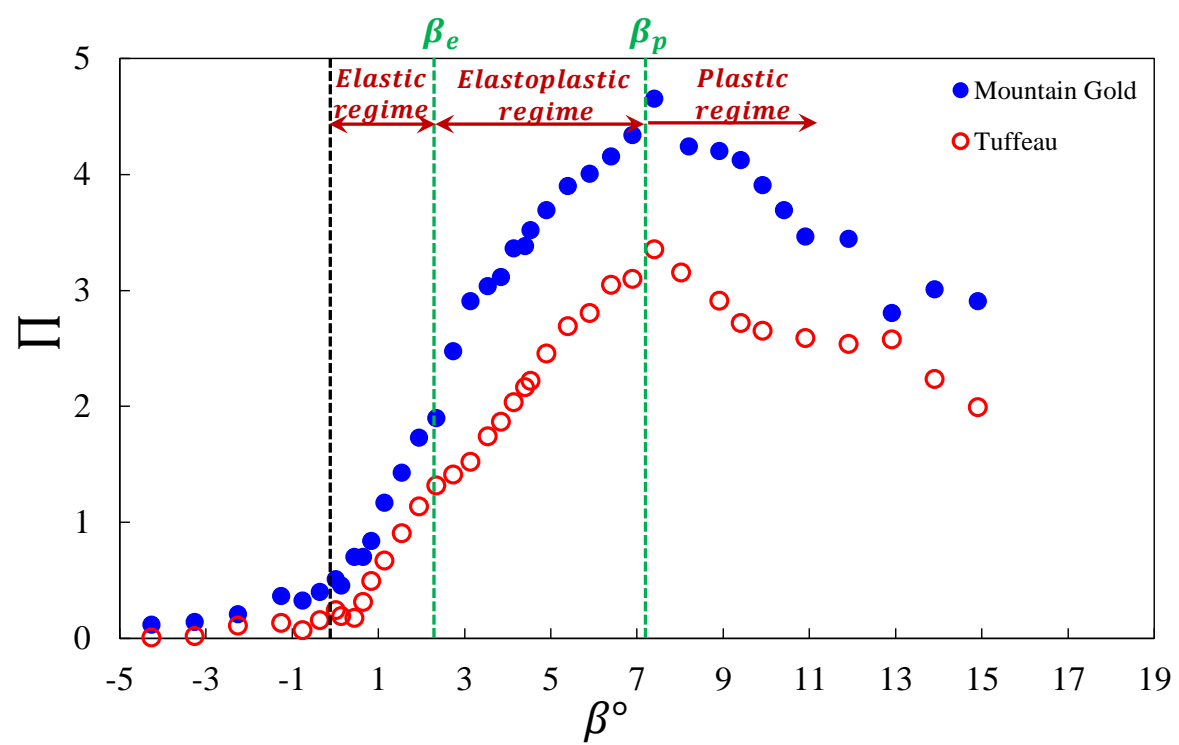

Figure 5: Scaled contact stress $\left(\prod\right)$ versus inclination angle $(\beta)$ at $\mathbf{d}=\mathbf{0 . 7 0}$ mm. Tests conducted on Tuffeau limestone and Mountain Gold sandstone [21, 22].

\section{Full scale drilling case}

It is generally accepted that different types of wear mechanism are in effect during the process of drilling including the steady wear as a result of abrasion and other wear modes, such as chipping, mostly caused by drilling dynamics. The wear flat studied in this work is mostly caused by the former mode of wear which erodes the cutter due to continuous frictional contact with the rock abrasive minerals. Normally, in the absence of drilling dynamic phenomena, this should be the predominant type of wear observed on a PDC cutter.

Limited information exists within the current literature relating the inclination angle $(\beta)$ to drilling parameters. Ersoy and Waller [63] reported that soft formations tend to wear the cutter at a higher inclination angle compared to hard/brittle formations. Remarks have been made by Zijsling and Djurre 64] that can lead to a general understanding of the range of $\beta$ values expected in 
practice. The document states that (supported by claimed field observations) the wear flat tends to create an angle of between $10^{\circ}$ to $15^{\circ}$ with the hole bottom.

If the observations stated above are accepted, results of this work may have immediate implications in hard/brittle rock drilling; among any other future applications. Glowka [65] observed that a PDC cutter "thermally accelerated wear" in hard rock drilling instigates when [in effect] the scaled contact stress $\left(\Pi=\frac{\sigma}{q}\right)$ is near or above 1.0. Therefore, to avoid this accelerated mode of wear and to prolong the bit run, it may be desirable to stay within the elastic regime of frictional contact for the rock types presented in Fig. 5 and Fig. 6

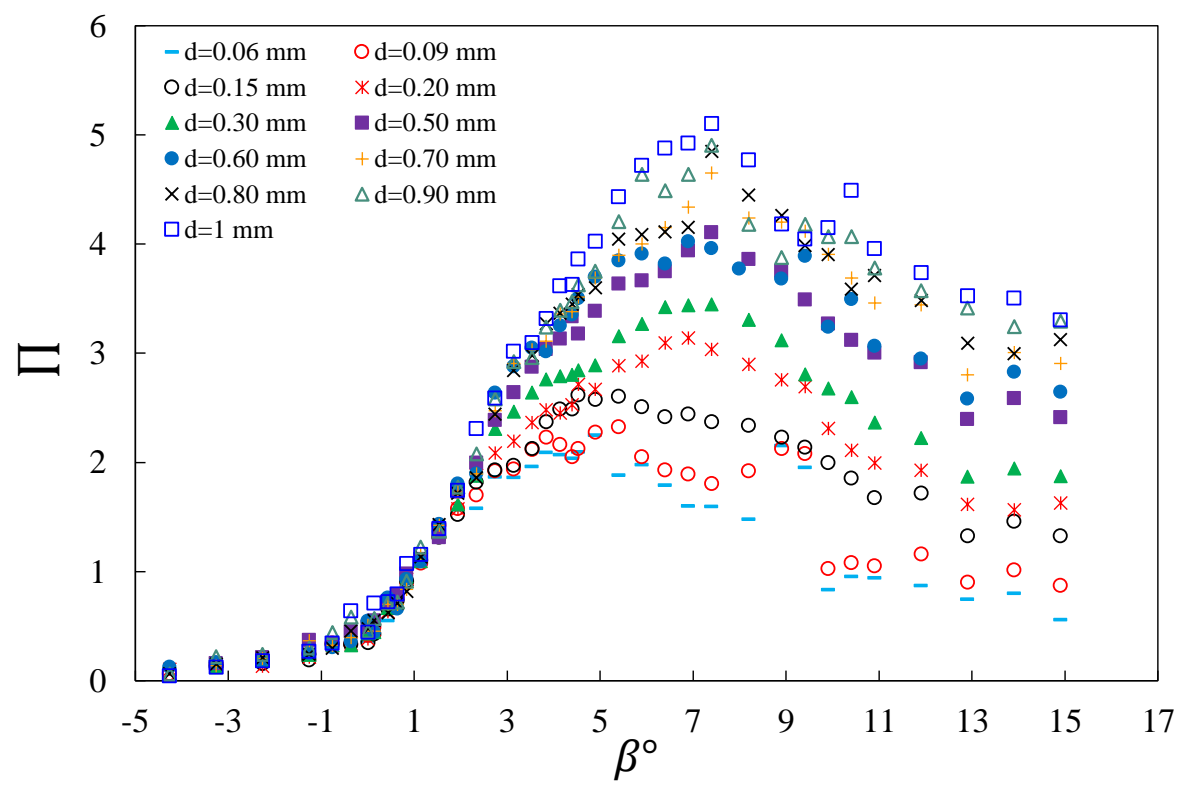

Figure 6: Scaled contact stress versus inclination angle at different depths of cut. Tests conducted on Mountain Gold sandstone [21, 48].

The inclination between the wear surface and the cutter velocity vector is controlled by the location of the cutter along the bit profile (in particular the radial distance $(R)$ with respect to the bit axis of rotation), the rate of penetra- 
tionon, and angular velocity (rotary speed). As a numerical example, consider drilling into a hard rock formation with an $8^{\frac{3}{4}}$ inch PDC bit that has already developed some wear flat on the cutters. Further, for example, let us assume that the magnitude of $\prod$ is near or less than 1.0 at $\beta<2^{\circ}$ for this rock type. Under the assumption that a wear flat has formed parallel to the rock surface (or in other words, perpendicular to drill-bit axis), the angle $\beta$ is given by:

$$
\beta \approx \tan (\beta)=\frac{R O P \cdot \cos \gamma}{5 N \cdot 2 \pi R}
$$

in which, $\mathrm{ROP}$ is rate of penetration in $\mathrm{ft} / \mathrm{hr}, N$ is rotary speed in rotation per minute, and $R$ is the radius from the bit center axis in inches, and $\gamma$ is the angle that the normal to bit profile makes with the bit axis. For the sake of simplicity, we only consider cutters on the nose area (assuming $R \approx 2.56$ inch) for which $\gamma \approx 0^{\circ}$, and therefore $\cos (\gamma) \approx 1$. Applying these parameters to the equation results in the condition of $N>\frac{R O P}{2.74}$ in order to have $\beta<2^{\circ}$ and minimize thermally accelerated wear. In other words, for instance, rotary speeds of less than $15 \mathrm{RPM}$ while drilling at $40 \mathrm{ft} / \mathrm{hr}$ are not advisable in terms of cutter wear. Although this numerical example may not be close enough to normal drilling parameters in the field to be of a concern, for formations with lower critical angles or certain bit profiles with lower angle cones, the minimum rotary speed may be much higher. Even in this same example, assuming a cone angle of $30^{\circ}$ for this bit, for the cutter(s) at 0.50 inch radius, we should have ${ }_{245} N>\frac{R O P}{0.63}$ before the cutter acceleration wear starts; i.e. the minimum rotary speed at $40 \mathrm{ft} / \mathrm{hr}$ would be $64 \mathrm{RPM}$.

This application example should be generic enough to be utilized in finding the inclination angle $(\beta)$ for given conditions (and cutters). However, the concept of limiting the inclination angle to a given range is only interpreted from the results presented here and is only applicable for the range of parameters discussed here (including depth of cut), see Fig 6 . Although one can anticipate similar rocks and/or operating conditions; no claim is made herein for such circumstances. The available data for several other rock types [21, 48, however, 
show similar behavior to that of Fig. 66 but are not included for briefness.

\section{${ }_{255}$ 5. Experimental setup}

\subsection{Scratching device and cutter holder}

The cutting apparatus used for the cutting tests is called the "Wombat" 1 machine which was designated to scratch rocks (using either a single blunt or a single sharp cutter) by tracing a groove on the rock surface (Fig. 7). The Wombat is a kinematically controlled apparatus, i.e. cutting tests are carried out under controlled depth of cut $(d)$ with a predetermined constant horizontal velocity $\left(\boldsymbol{v}=4 \frac{\mathrm{mm}}{\mathrm{s}}\right)$ along the entire cut, while the tangential $\left(F_{s}\right)$ and normal $\left(F_{n}\right)$ components of the total force acting on the cutter are recorded separately with a precision less than $1 \mathrm{~N}$ over a range of 0 to $\pm 3500 \mathrm{~N}$. Note that all cutting tests in this study were based on the standard procedure explained in several references such as [21, 24, 66].

\footnotetext{
${ }^{1}$ This machine is housed in the Rock Mechanics Testing Laboratory, CSIRO, Perth, Australia.
} 


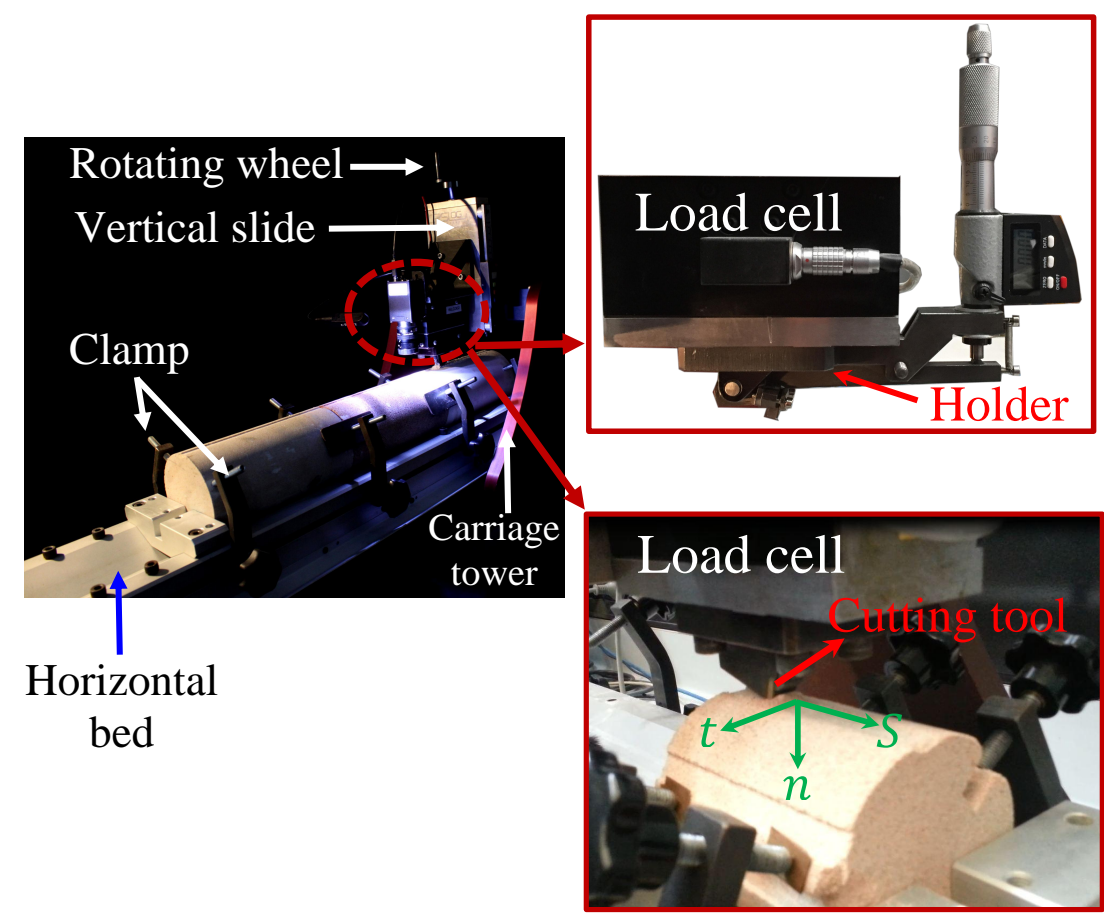

Figure 7: The rock cutting machine.

A unique cutter holder was designed (using AutoCad 2015) and manufactured to adjust the back rake angle of the cutter $\theta$ (and therefore the inclination angle $\beta$ ) by steps of $0.10^{\circ}$ [21, 22]. The main mechanical parts of this novel cutter holder are shown in Fig. 8. 


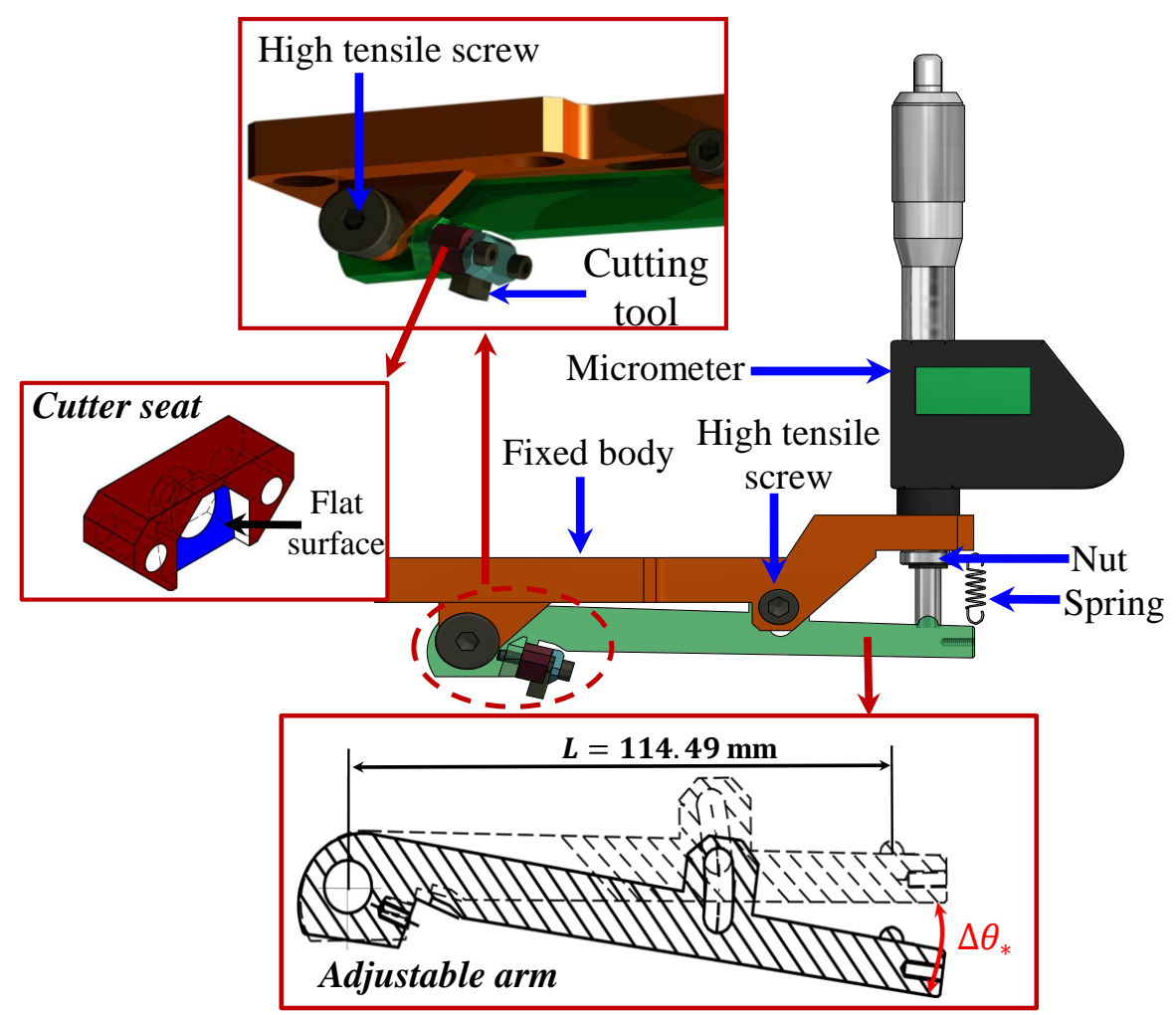

Figure 8: Schematic of the new cutter holder with fine adjustable inclination angle.

As the blunt cutter is mounted on the cutter seat of the cutter holder with a forward inclination $\left(\theta \geq 0^{\circ}\right)$, the back rake angle of the cutter is first set to an initial back rake angle $\left(\theta_{*}\right)$ and then incrementally increased by step of $\Delta \theta_{*}$ to reach the desired value of back rake angle $\theta\left(\theta=\theta_{*}+\Delta \theta_{*}\right)$. Therefore, the inclination angle of wear flat surface (Fig. 9) is derived by:

$$
\beta=\chi-\theta_{*}-\Delta \theta_{*}
$$

where $\chi$ is the chamfer angle of the blunt cutter (and is a constant value for a given blunt cutter and defined as the angle between the wear flat surface and 
the direction of velocity vector when $\theta=0^{9}{ }^{2}$, see Fig. $9 \mathrm{a}$, and $\Delta \theta_{*}$ can be written as:

$$
\Delta \theta_{*}=\arcsin \left(\frac{\Delta z}{L}\right)
$$

the radius of rotation, see Fig. 8 . Note that the procedure and validation of the method of measuring $\beta$ is well described in Refs. [21, 22, 48].

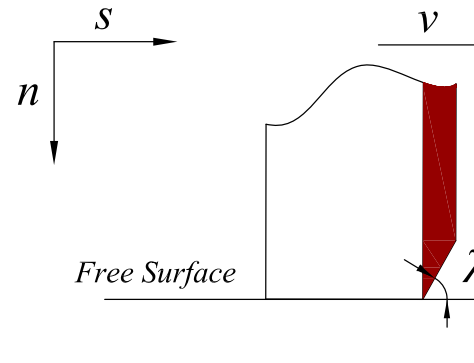

(a)

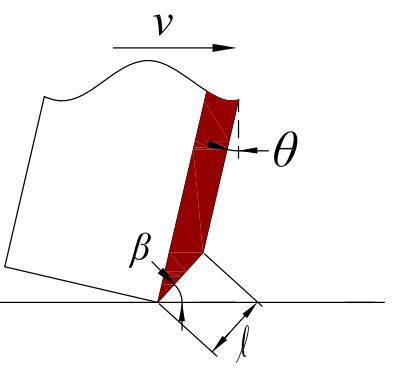

(b)

Figure 9: Definition of $(a)$ the chamfer angle $\chi$, and $(b)$ the inclination angle $\beta$ between the wear flat surface of a blunt PDC cutter and the velocity vector $(v)$.

\subsection{Cutters specifications}

Two rectangular shaped PDC cutters (one sharp and one blunt) were used in this research with a width of $10 \mathrm{~mm}(\omega=10 \mathrm{~mm})$. Note that the wear flat surface of a blunt cutter is precisely machined by grinding an originally sharp cutter. The main geometrical properties of both the sharp and blunt cutters used for cutting tests are presented in Table 1. In order to measure the length of a wear flat $(\ell)$ and the chamfer angle $(\chi)$, as schematically shown in Fig. 99 a high resolution optical microscope (model AxioScope Imager A1) was used [21].

\footnotetext{
${ }^{2}$ The chamfer angle is also defined as the angle between the wear flat surface and the normal to the cutting face.
} 
Table 1: Geometrical specifications of the cutters used for testing [21].

\begin{tabular}{c|cc|}
\hline Cutter geometry & Sharp cutter & Blunt cutter \\
\hline \hline Width $(\mathrm{mm})$ & 10 & 10 \\
Wear flat length $(\mathrm{mm})$ & 0 & 1 \\
Wear flat area $\left(\mathrm{mm}^{2}\right)$ & 0 & 10 \\
Chamfer angle & $0^{\circ}$ & $18.44^{\circ}$ \\
\hline
\end{tabular}

\subsection{Rock samples}

One limestone (Tuffeau) and one sandstone (Mountain Gold) sample were investigated for the purpose of this study, and were selected based on their homogeneity and isotropic behavior in relation to rock cutting (meaning the cutting response is not affected by the direction in which the cut is carried out). The mechanical and physical properties of these two rock samples are listed in Table 2. The methods used to determine the physical properties of the rock samples are detailed in Refs. [21, 22].

Table 2: Mechanical and physical properties of rocks used in this study [21].

\begin{tabular}{|c|ccc|}
\hline \multicolumn{2}{c}{ Rock name } & Tuffeau & Mountain Gold \\
\hline \hline Uniaxial compressive strength (MPa) & 8.51 & 34 \\
Elastic modulus (GPa) & 1.70 & 8.10 \\
Poisson's ratio & 0.24 & 0.20 \\
Dry Porosity (\%) & 41.49 & 15.70 \\
Dry density $\left(\mathrm{Kg} / \mathrm{m}^{3}\right)$ & 1360 & 2180 \\
Permeability $(\mathrm{mD})$ & 39.07 & 2.09 \\
$\frac{E^{*}}{q}$ & & 211.97 & 248.16 \\
& & 24 & 8 \\
Grain size distribution diameters & $D_{10}(\mu \mathrm{m})$ & 401 \\
& $D_{50}(\mu \mathrm{m})$ & 181 & 792 \\
\hline
\end{tabular}

$D_{10}$ is the diameter at which $10 \%$ of a sample's mass is comprised of smaller particles. $D_{50}$ is the diameter at which $50 \%$ of a sample's mass is comprised of smaller particles. $D_{90}$ is the diameter at which $90 \%$ of a sample's mass is comprised of smaller particles. 


\section{Results and discussion}

A series of cutting tests using a new sharp PDC cutter was first carried out to characterize the force associated with the pure cutting process as a function of the back rake angle based on Eq. 2. Those results were then used to estimate the force mobilized on the wear flat from the total force recorded during tests carried out with a blunt cutter at similar back rake angle (see Eq. 5); and eventually the contact stress $(\sigma)$ mobilized across the wear flat surface (see Eqs. 4 and 6] 22, 48]. The inclination angle $(\beta)$ of the blunt cutter was varied in an interval of $-4.26^{\circ}$ to $14.90^{\circ}$ while the depth of cut ranges from 0.03 to $1 \mathrm{~mm}$.

\subsection{Effect of depth of cut on the frictional contact}

A series of laboratory cutting experiments was performed with the blunt cutter on the samples of Tuffeau limestone and Mountain Gold sandstone at a wide range of depths of cut. According to the three regimes of frictional contact (elastic, elastoplastic and plastic) presented in the literature [21, 22] and Fig. 5. three values of the inclination angles were selected; $0.44^{\circ}, 5.40^{\circ}$ and $9.41^{\circ}$ which correspond to the elastic, elastoplastic and plastic regimes, respectively [21, 22].

In Fig. 10 and Fig. 11 are shown the plots of scaled contact stress $\left(\prod=\frac{\sigma}{q}\right)$ at the wear flat-rock interface as a function of depth of cut $(d)$ for Tuffeau and Mountain Gold, respectively. The results clearly indicate that the depth of cut has a significant effect on the response of cutting with a single blunt cutter in the elastoplastic regime and particularly plastic regime. However as shown in the figures below, the contact stress remains invariant with an increase in depth of cut for both rock samples when the regime of frictional contact between a blunt cutter and the substrate is within the elastic regime (for small inclination angles $0^{\circ} \leq \beta \leq 2^{\circ}$ ). 


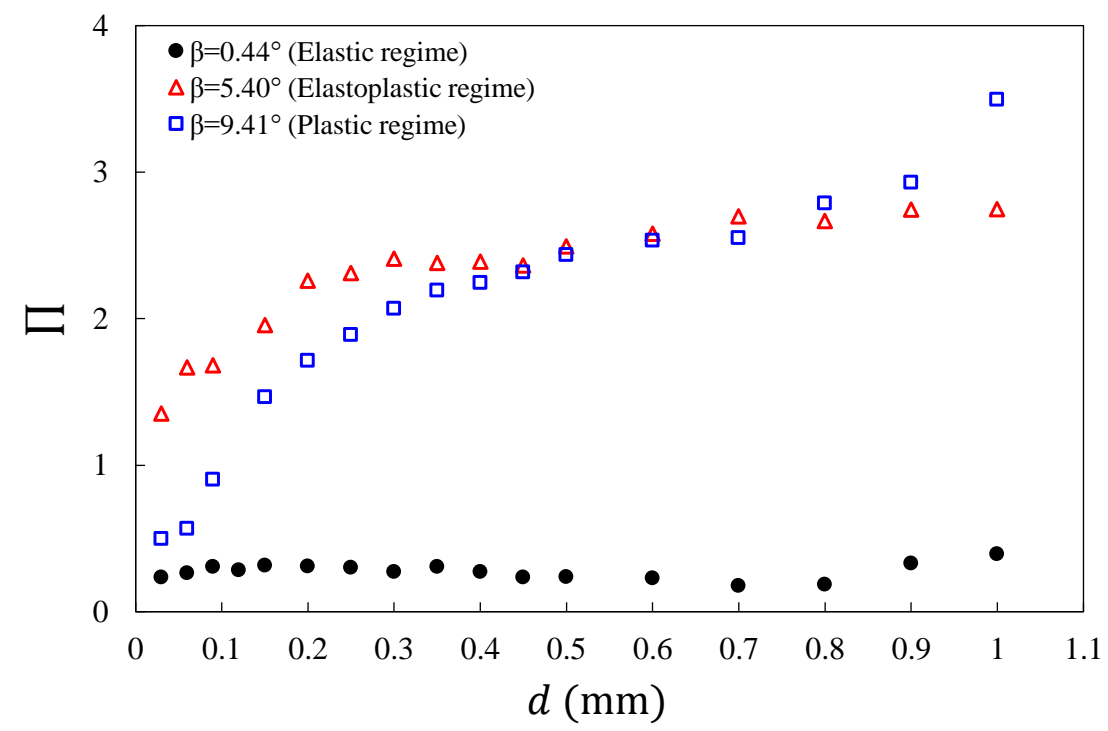

Figure 10: Plot of scaled contact stress $\left(\prod\right)$ as a function of depth of cut $(d)$ at three different inclination angles $(\beta)$. Tests conducted on Tuffeau limestone.

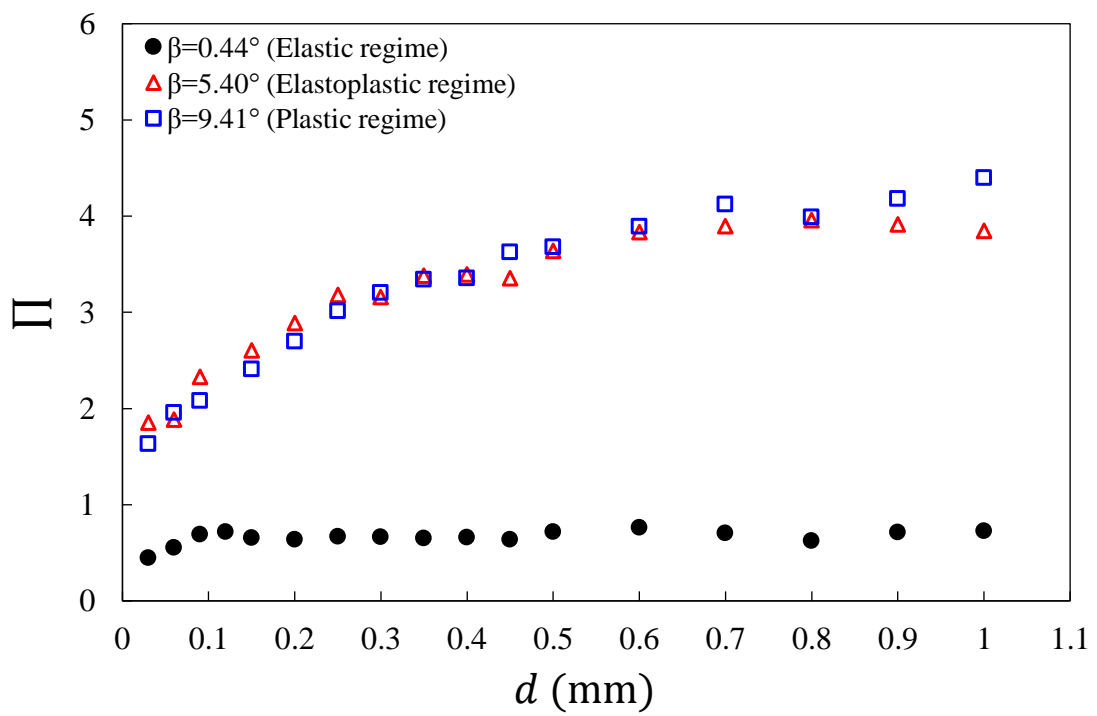

Figure 11: Plot of scaled contact stress $(\Pi)$ as a function of depth of cut $(d)$ at three different inclination angles $(\beta)$. Tests conducted on Mountain Gold sandstone. 
Within the elastoplastic regime, the contact stress progressively increases with the depth of cut (consistent with the results of Lhomme (1999)) and then saturates at a limit value when the depth of cut reaches a critical depth of cut denoted as $d_{*}$. This observed trend could be attributed to the fact that, at shallow depths of cut, it is postulated that the two contacting surfaces (wear flat surface of the blunt cutter and the rock samples) are not entirely conforming. Hence, the contact stress is proportional to the depth of cut, in other words, any increase in depth of cut $(d)$ leads to an increase in the cutting force associated with the pure cutting process and also in the effective contact area $A_{f}$ (or length of wear flat surface $\ell$ ) before the depth of cut reaches $d_{*}$ (function of bit bluntness 335 20, 51] $)$. Beyond the critical depth of cut $\left(d \geq d_{*}\right)$, the normal component of frictional force stabilizes at a stationary value and therefore the effective contact stress has also reached a limited value. In this phase, the incremental cutting response is governed by the pure cutting process. These findings are in good agreement with the results of other studies [42, 50, 51].

It is interesting to note that the magnitude of the critical depth of cut is roughly similar for both rock samples (Tuffeau and Mountain Gold) but increases steadily with the inclination angle $(\beta)$. As supported by results shown in Fig. 12 at a wide range of inclination angles, one can intuitively argue that the critical depth of cut $\left(d_{*}\right)$ scales with the normal height of the wear flat 345 (where the term "normal" means measured in a plane normal to the velocity vector). Note that past the inclination angle of $\beta \simeq 11.91^{\circ}$, the critical depth of cut could not be estimated as the depth of cut was limited to $0.80 \mathrm{~mm}$. 


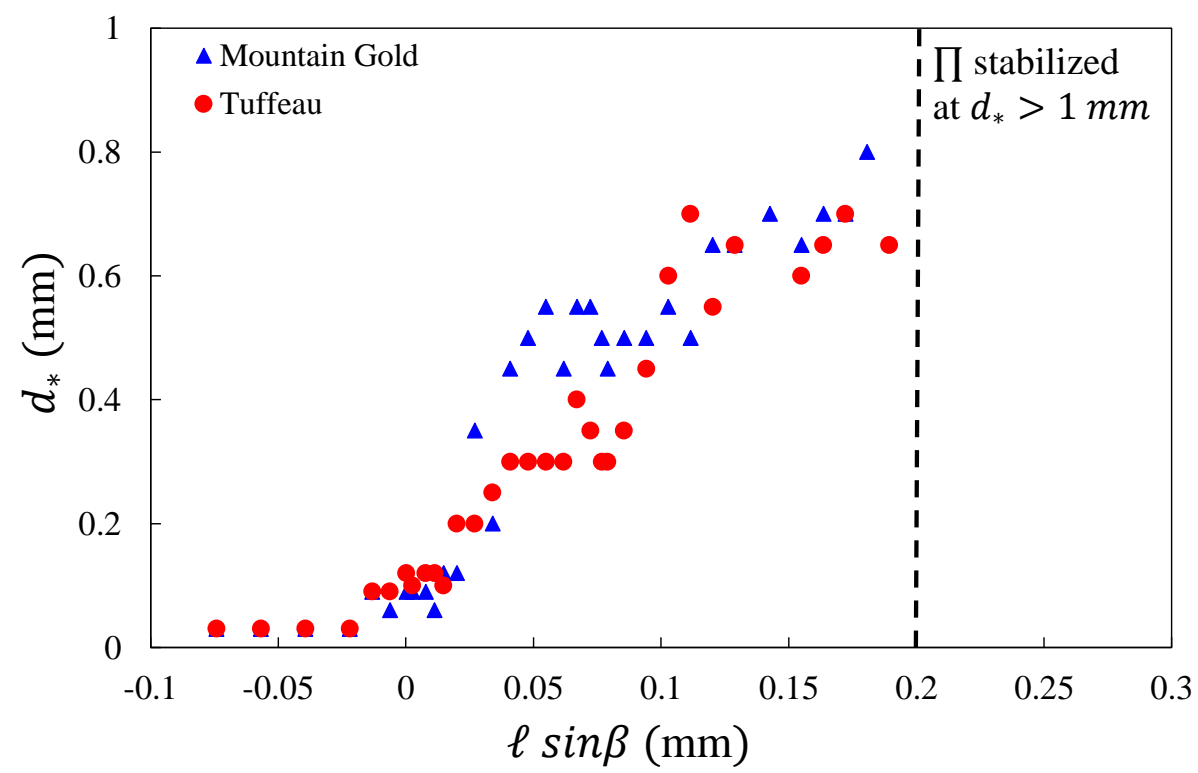

Figure 12: Evolution of stabilized value of depth of cut $\left(d_{*}\right)$ as a function of height of the wear flat surface $(\ell \sin \beta), d_{*} \simeq 4 \ell \sin \beta$.

The effect of depth of cut on the apparent contact stress has sometimes been related to an actual increase of the effective contact area between the cutter and the rock, with an increase of depth of cut converging towards a more conformal contact. A similar explanation invokes the volume of rock being forced underneath the cutter, as the depth of cut increases this volume increases steadily (up to a limit) which in turn affects the resulting contact stress. As a result, the extent of the elastoplastic region increases with the depth of cut and eventually converges at a depth of cut of about $0.70-0.80 \mathrm{~mm}$ in the current examples [67. Visual observations support this explanation as tests carried out at large depth of cut in the plastic regime $\left(\beta \simeq 7^{\circ}-9.5^{\circ}\right)$ are accompanied by a clear accumulation of powder in the bottom of the groove, as compared with the tests performed at a shallower depth of cut. Consequently, although this is not included in the original bit-rock interaction model proposed by Detournay and Defourny [14, it can be deduced from these results that the frictional force as well as the contact stress are dependent on the depth of cut. These 
observations suggest that the assumption that the forces acting on the wear flat are independent of the cutting process taking place ahead of the cutter, is invalid and is discussed analytically in the following section.

\subsection{Review of two independent processes}

The experimental results presented in this study suggest that the total force acting on a blunt cutter cannot be captured by the simple addition of the force measured on an inclined wear flat in contact with the rock, and the one measured on a sharp cutter at the same depth of cut and back rake angle. This is particularly true for large inclination angles.

The immediate implication of the results presented in this paper is questioning the common assumption that allows bit-cutter performance models to decouple the wear flat from the cutting face. Although a convenient assumption to enable combining models for sharp cutters and those of frictional sliders, here it is demonstrated that significant errors may result from such an assumption.

Below we simply compare the force recorded on a blunt cutter at a back rake angle $(\theta)$ at depth of cut $(d)$ with the force recorded on the same blunt cutter but with only the wear surface in contact with the rock $d_{1}$ and the force recorded 380 on a sharp cutter for the same back rake angle $(\theta)$ and depth of cut $d-d_{1}$, see Fig. 13. Results summarized in Table 3 implies that the cutting response of the blunt cutter is not simply the sum of the forces independently measured on the wear flat and on the cutting face $(\Delta F)$. The results in Table 3 clearly indicate that there is a noticeable difference between the values of normal and tangential components of the forces acting on the cutting face of a blunt cutter $(\Delta F)$ and the similar force components acting on the cutting face of a sharp cutter. 
Table 3: Comparison of force responses acting on a sharp cutter and a blunt cutter at different inlcination angles.

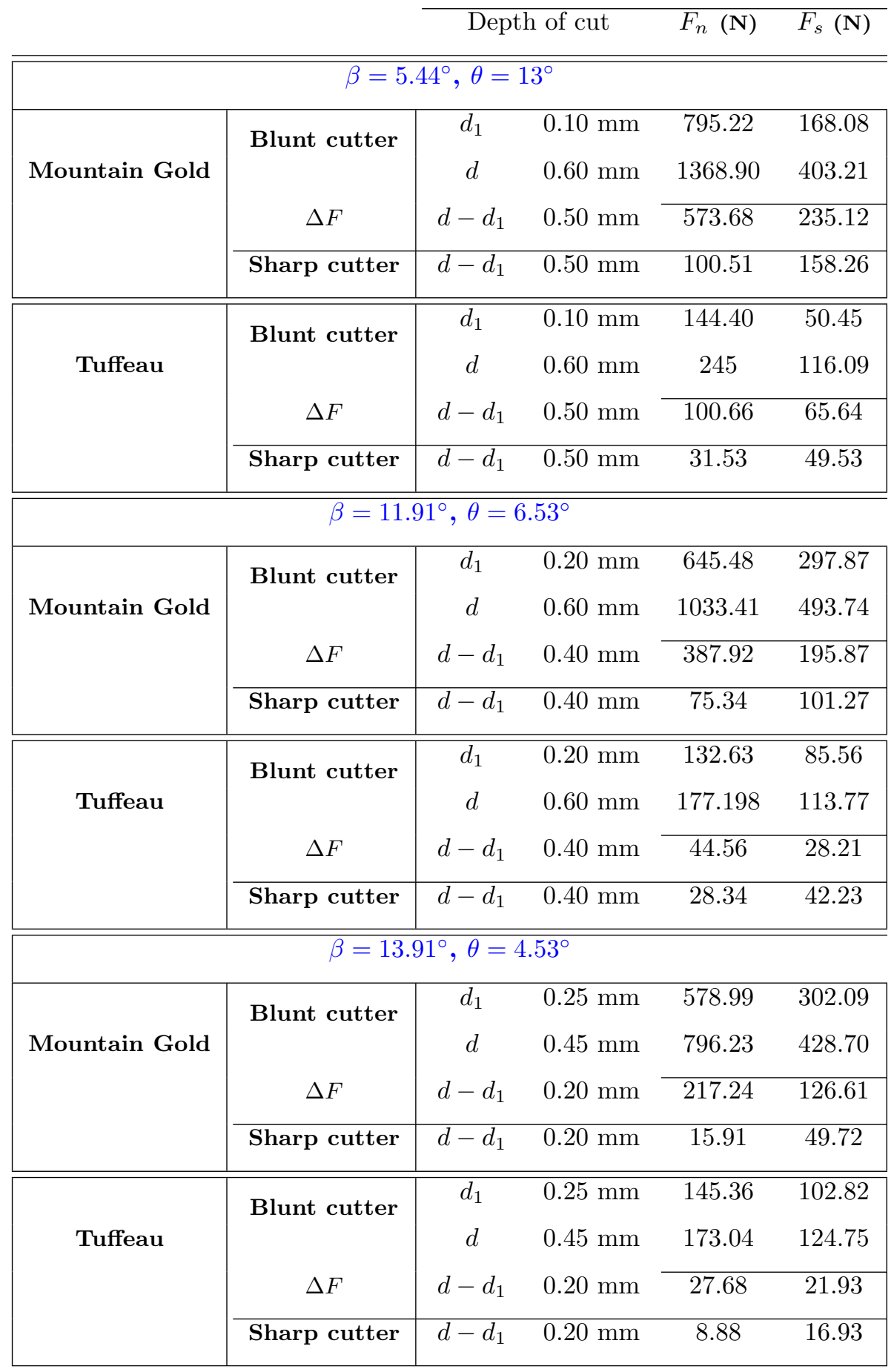


As discussed in the literature [14, 51, the incremental response of a blunt cutter is similar to the one of a sharp cutter beyond a critical depth of cut; but as well illustrated in the results shown in Fig. 14a to Fig. 14f for Mountain Gold sandstone, the threshold depth of cut $d_{*}$ is found significantly larger than the projection of the wear flat length in the plane normal to the groove $\left(d_{*}>d_{1}\right)$, see Fig. 15. At large inclination angle (where the wear flat acts more as chamfer or secondary cutting face), the incremental cutting response has not converged towards the response of a sharp cutter at a depth of cut associated with the onset of the brittle cutting regime $(d>1.2 \mathrm{~mm})$. As mentioned in the previous section, the possible explanation for this observation is the relative backward flow of the crushed particles which were visually observed during the experimental tests. The results of Tuffeau limestone compared with Mountain Gold sandstone are also presented in Appendix A Also, the evolution of $d_{*}$ as a function of the inclination angle $(\beta)$ is presented in Appendix B.

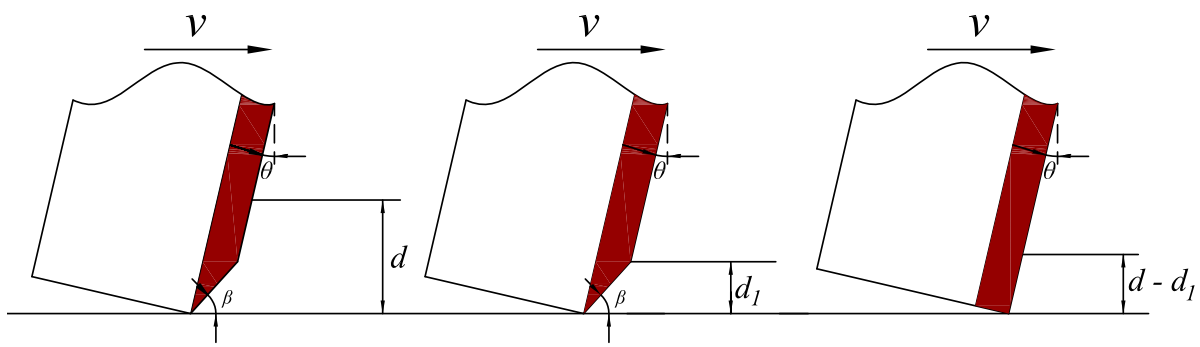

Figure 13: Schematic of two blunt cutters and a sharp cutter with the same back rake angles and different depths of cut. 


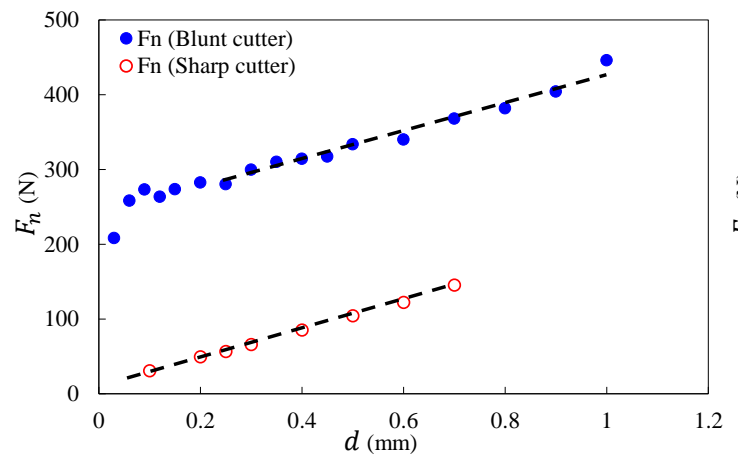

(a) $\beta=0.64^{\circ}, \theta=17.80^{\circ}$

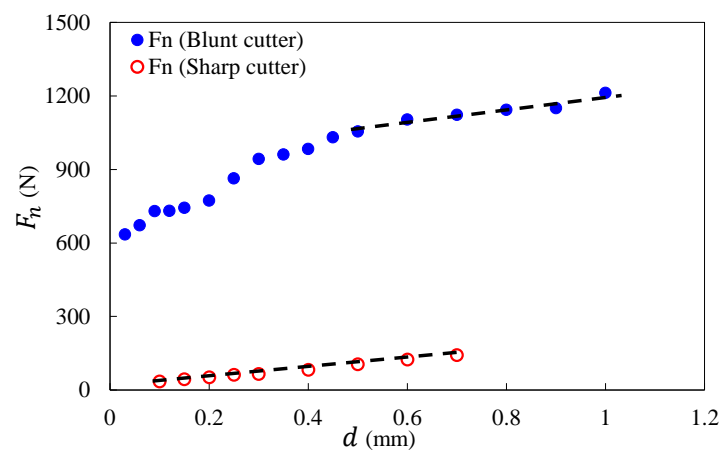

(c) $\beta=3.58^{\circ}, \theta=14.86^{\circ}$

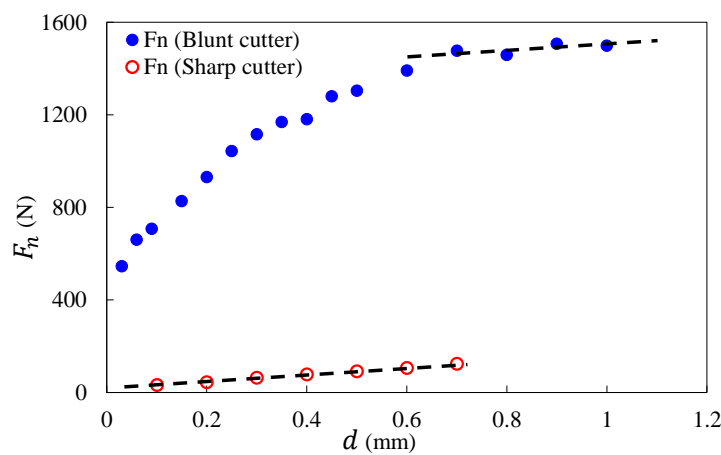

(e) $\beta=9.40^{\circ}, \theta=9.04^{\circ}$

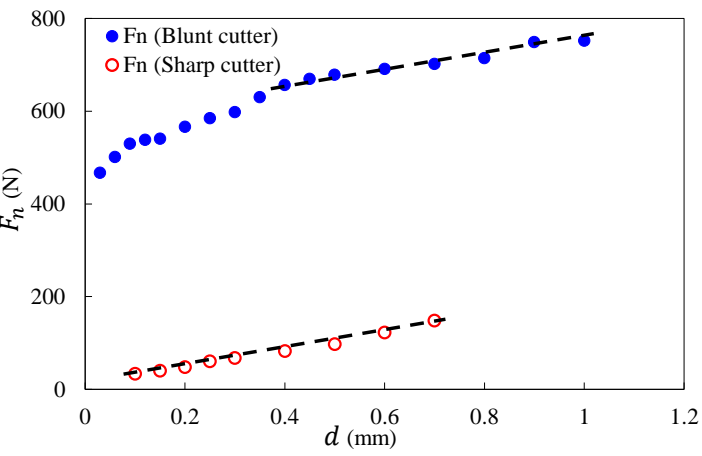

(b) $\beta=1.94^{\circ}, \theta=16.50^{\circ}$

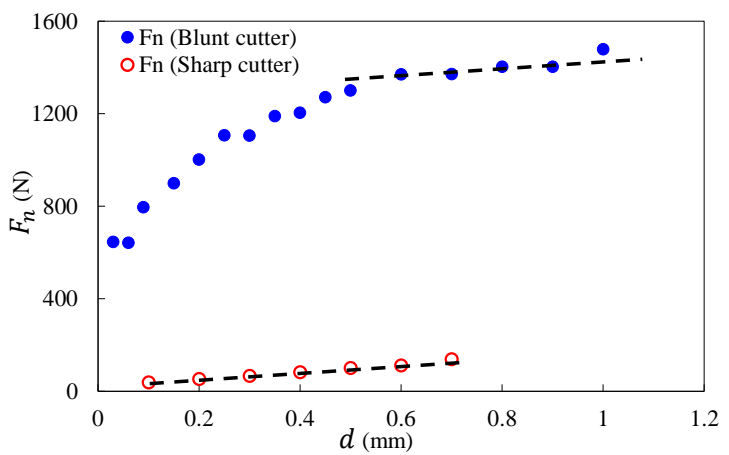

(d) $\beta=5.40^{\circ}, \theta=13.04^{\circ}$

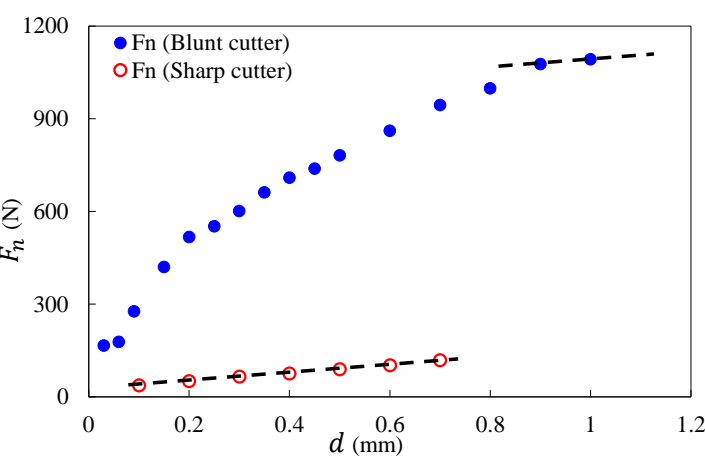

(f) $\beta=14.90^{\circ}, \theta=3.54^{\circ}$

Figure 14: Evidence of $d_{*}$ with increase of inclination angle $(\beta)$. Tests conducted on Mountain Gold sandstone. 


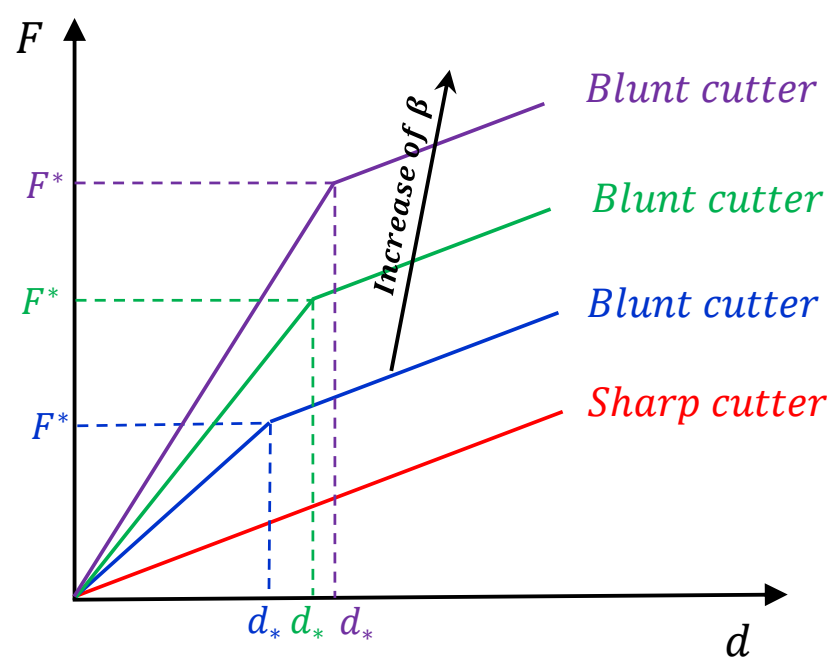

Figure 15: Schematic of the normal behavior of a sharp cutter and a blunt cutter as a function of depth of cut.

\section{Conclusions}

In the present study, results of cutting tests using a single blunt PDC (Polycrystalline Diamond Compact) cutter and a single sharp PDC cutter conducted in two different rock samples (a coarse grain sandstone and a soft grain limestone) were presented. An extensive and comprehensive set of cutting tests was carried out not only on a wide range of depths of cut but also at different inclination angles of the wear flat. A unique cutter holder was purposely designed and manufactured along with a precise experimental protocol implemented so as to change the angle of inclination $(\beta)$ in steps of $0.10^{\circ}$.

The experimental results indicate that the contact force (and therefore the contact stress $\sigma$ ) at the wear flat-rock interface is affected by both the depth of cut (or rate of penetration $\mathrm{ROP}$ ) and the inclination angle $(\beta)$. In view of the three regimes of frictional contact (identified as elastic, elstoplastic and fully plastic) were introduced in the previous studies [21, 22], the normal contact 415 stress remains unchanged within the elastic regimes which typically occurs at 
small inclination angles. Within the elastoplastic regime of the frictional contact, the findings of this study is consistent with the work of Adachi (1996); the contact stress increases with depth of cut due to non-conformal contact at the wear flat-rock interface and then it levels off once the depth of cut $(d)$ reaches $d_{*}$. When the regime of interaction between the wear flat and the substrate is within the plastic regime, the contact stress increases steadily with the depth of cut.

The findings of this research have also shown that the two simultaneous processes of rock cutting, frictional contact and pure cutting, cannot simply be considered as fully independent processes. The incremental response of a blunt cutter becomes similar to the response of a sharp cutter beyond a depth of cut $\left(d_{*}\right)$ which is significantly larger than the wear flat projected normal height $\left(d_{c r}=\ell \sin \beta\right)$. Also, the results indicate that for a large inclination angle $\left(\beta>7^{\circ}\right.$, for which the wear flat acts more as a chamfer or second cutting face [22]) the incremental response of the cutter has not yet converged to the response of a sharp cutter beyond a depth of cut greater than $1 \mathrm{~mm}$ at, which the occurrence of the brittle regime occurs.

This research implies that the drilling with a PDC drag bit or cutting model with a single blunt cutter cannot readily be considered as two independent

${ }_{435}$ "pure cutting" and "frictional contact" processes, Also, value of the inclination angle of the wear flat has a significant effect on the cutting response of a drag bit. This finding plays an important role in analysis of the data obtained from laboratory experiments and in particular, the numerical simulations of rock cutting which are generally based on many simplifications. Further work (such as finite element modeling (FEM) and/or discrete element modeling (DEM)) is necessary to compare the experimental results with numerical modeling.

\section{Acknowledgment}

The first author would like to thank Joel Sarout and Jeremie Dautriat from CSIRO (Perth, Australia) for granting access to the Rock Mechanics Testing 
Thomas Richard (from Epslog Engineering SA) for his beneficial discussions and supervision. The work has been supported by the Deep Exploration Technologies Cooperative Research Centre whose activities are funded by the Australian Government's Cooperative Research Centre Programme. This is DET CRC

Document 2018/1077.

\section{References}

[1] L. Gerbaud, S. Menand, H. Sellami, PDC bits: All comes from the cutter rock interaction, IADC/SPE Drilling Conference, 21-23 February, Miami, Florida, USA, Society of Petroleum Engineers, 2006.

455

[2] F. Bellin, A. Dourfaye, W. King, M. Thigpen, The current state of PDC bit technology, World oil 231 (2010).

[3] S. Niu, H. Zheng, Y. Yang, L. Chen, Experimental study on the rockbreaking mechanism of disc-like hybrid bit, Journal of Petroleum Science and Engineering (2017).

460

[4] L. F. Franca, A bit-rock interaction model for rotary-percussive drilling, International Journal of Rock Mechanics and Mining Sciences 48 (2011) $827-835$.

[5] J. F. Brett, T. M. Warren, S. M. Behr, A. P. Co., Bit whirl: A new theory of PDC bit failure, SPE Annual Technical Conference and Exhibition,

[6] Y. Ma, Z. Huang, Q. Li, Y. Zhou, S. Peng, Cutter layout optimization for reduction of lateral force on PDC bit using kriging and particle swarm optimization methods, Journal of Petroleum Science and Engineering 163 (2018) $359-370$.

470

[7] B. Akbari, Polycrystalline diamond compact bit-rock interaction, M. Sc Thesis, Memorial University of Newfoundland, 2011. 
[8] M. Yahiaoui, J.-Y. Paris, K. Delbé, J. Denape, L. Gerbaud, A. Dourfaye, Independent analyses of cutting and friction forces applied on a single polycrystalline diamond compact cutter, International Journal of Rock Mechanics and Mining Sciences 85 (2016) 20-26.

[9] T. M. Warren, L. A. Sinor, PDC bits: what's needed to meet tomorrow's challenge, University of Tulsa Centennial Petroleum Engineering Symposium, 29-31 August, Tulsa, Oklahoma, Society of Petroleum Engineers, 1994.

[10] B. Akbari, S. Miska, The effects of chamfer and back rake angle on PDC cutters friction, Journal of Natural Gas Science and Engineering 35 (2016) 347-353.

[11] M. Yahiaoui, J.-Y. Paris, K. Delbé, J. Denape, L. Gerbaud, C. Colin, O. Ther, A. Dourfaye, Quality and wear behavior of graded polycrystalline diamond compact cutters, International Journal of Refractory Metals and Hard Materials 56 (2016) 87-95.

[12] N. Challamel, H. Sellami, Application of yield design for understanding rock cutting mechanism, SPE/ISRM Rock Mechanics in Petroleum Engineering, Society of Petroleum Engineers, 1998.

[13] D. A. Glowka, Development of a method for predicting the performance and wear of PDC (polycrystalline diamond compact) drill bits, Technical Report, Sandia National Labs., Albuquerque, NM (USA), 1987.

[14] E. Detournay, P. Defourny, A phenomenological model for the drilling action of drag bits, International Journal of Rock Mechanics and Mining Sciences \& Geomechanics Abstracts 29 (1992) 13-23.

[15] A. Wojtanowicz, E. Kuru, Mathematical modeling of PDC bit drilling process based on a single-cutter mechanics, Journal of Energy Resources Technology 115 (1993) 247-256. 
[16] C. Fairhurst, W. Lacabanne, Hard rock drilling techniques, Mine Quarry Eng 23 (1957) 157-161.

[17] D. Zijsling, Analysis of temperature distribution and performance of polycrystalline diamond compact bits under field drilling conditions, SPE annual technical conference and exhibition, 16-19 September, Houston, Texas, Society of Petroleum Engineers, 1984.

[18] Y. Zhou, W. Zhang, I. Gamwo, J.-S. Lin, Mechanical specific energy versus depth of cut in rock cutting and drilling, International Journal of Rock Mechanics and Mining Sciences 100 (2017) 287 - 297.

[19] B. Besselink, Analysis and validation of self-excited drill string oscillations, M. Sc Thesis, Department of Mechanical Engineering, Eindhoven University of Technology, 2008.

[20] Y. Zhou, E. Detournay, Analysis of the contact forces on a blunt PDC bit, ARMA 14-7351, 48th US Rock Mechanics / Geomechanics Symposium, ARMA, 2014.

[21] I. Rostam Sowlat, Effect of cutter and rock properties on the frictional contact in rock cutting with blunt tools, Ph.D. thesis, Curtin University, 2017.

[22] I. Rostamsowlat, T. Richard, B. Evans, Experimental investigation on the effect of wear flat inclination on the cutting response of a blunt tool in rock cutting, Acta Geotechnica (2018) 1-16.

[23] G. Mensa-Wilmot, Impact resistant PDC drill bit, 2013. US Patent $8,448,725$.

[24] T. Richard, F. Dagrain, E. Poyol, E. Detournay, Rock strength determination from scratch tests, Engineering Geology 147-148 (2012) 91-100.

[25] M. E. Merchant, Mechanics of the metal cutting process. i. orthogonal cutting and a type 2 chip, Journal of Applied Physics 16 (1945) 267-275. 
[26] M. E. Merchant, Mechanics of the metal cutting process. ii. plasticity conditions in orthogonal cutting, Journal of Applied Physics 16 (1945) 318-324.

[27] P. Jogi, W. Zoeller, The application of a new drilling model for evaluating formation and downhole drilling conditions, Petroleum Computer Conference, Society of Petroleum Engineers, 1992.

[28] I. Evans, The force required to cut coal with blunt wedges, International Journal of Rock Mechanics and Mining Science and Geomechanics Abstracts 2 (1965) 1-12.

[29] Y. Nishimatsu, The mechanics of rock cutting, International Journal of Rock Mechanics and Mining Sciences \& Geomechanics Abstracts 9 (1972) 261-270.

[30] M. Lebrun, Etude thique et expmentale de l'abattage Ingerie mnique; Application conception des machines d'abattage et de creusement, Ph.D Thesis, Ecole Nationale Supeure Des Mines de Paris, Fontainebleau, 1978.

[31] G. P. Cherepanov, M. I. Vorozhtsov, R. M. Eigeles, Rock cutting, Soviet Physics Doklady 32 (1987) 728-730.

[32] D. A. Glowka, Use of single-cutter data in the analysis of PDC bit designs: Part 1-development of a PDC cutting force model, Journal of Petroleum Technology 41 (1989) 797-849.

[33] T. Warren, A. Sinor, Drag-bit performance modeling, SPE Drilling Engineering 4 (1989) 119-127.

[34] J. B. Cheatham, W. H. Daniels, A study of factors influencing the drillability of shales - single-cutter experiments with stratapax drill blanks, ASME Journal of Energy Resources Technology 101 (1979) 189-195.

[35] T. Richard, Determination of Rock Strength from Cutting Tests, M. Sc Thesis, Faculty of the Graduate School of the University of Minnesota, Minneapolis, Minnesota, USA, 1999. 
[36] Y. Zhou, J.-S. Lin, Modeling the ductile-brittle failure mode transition in rock cutting, Engineering Fracture Mechanics 127 (2014) 135 - 147.

[37] Y. Zhou, J. S. Lin, On the critical failure mode transition depth for rock cutting, International Journal of Rock Mechanics and Mining Sciences 62 (2013) 131-137.

[38] W. Liu, X. Zhu, J. Jing, The analysis of ductile-brittle failure mode transition in rock cutting, Journal of Petroleum Science and Engineering 163 (2018) $311-319$.

[39] J. Almenara, E. Detournay, Cutting experiments in sandstones with blunt PDC cutters, Rock Characterization: ISRM Symposium, Eurock'92, Chester, UK, 14-17 September 1992, Thomas Telford Publishing, 1992, pp. $215-220$.

[40] W. W. Samiselo, Rock-Tool Friction as a Cuttability Predictor, M.Sc Thesis, Imperial College, London, United Kingdom, 1992.

[41] C. Lasserre, Rock friction apparatus: Realisation de tests de coupe sur roches a l'Aide d'un outil PDC, Technical Report, Institut en Sciences et Technologies Geophysique et Geotechniques, Universite de Paris VI, Paris, France, 1994.

[42] J. I. Adachi, Frictional contact in rock cutting with blunt tools, M. Sc Thesis, Civil Engineering, University of Minnesota, 1996.

[43] R. Teale, The concept of specific energy in rock drilling, International Journal of Rock Mechanics and Mining Sciences \& Geomechanics Abstracts 2 (1965) 57-73.

[44] T. Richard, E. Detournay, A. Drescher, P. Nicodeme, D. Fourmaintraux, The scratch test as a means to measure strength of sedimentary rocks, SPE 47196, SPE/ISRM Eurock 98, Society of Petroleum Engineers, Trondheim, Norway, 1998, pp. 1-8. 
[45] E. Detournay, A. Drescher, P. Defourny, D. Fourmaintraux, Assessment of rock strength properties from cutting tests: Preliminary experimental evidence, volume 1, Proc. of the Colloquium Mundanum on Chalk and Shales, Brussels, 1995, pp. 13-1.

[46] M. Theodoridou, F. Dagrain, I. Ioannou, Micro-destructive cutting techniques for the characterization of natural limestone, International Journal of Rock Mechanics and Mining Sciences 76 (2015) 98 - 103.

[47] I. Rostamsowlat, T. Richard, B. Evans, An experimental study of the effect of back rake angle in rock cutting, International Journal or Rock Mechanics and Mining Sciences 107 (2018).

[48] I. Rostamsowlat, Effect of cutting tool properties and depth of cut in rock cutting: An experimental study, Rock Mechanics and Rock Engineering (2018) 1-14.

[49] T. Lhomme, Frictional contact at a rock-tool interface: An experimental study, M. Sc Thesis, University of Minnesota, 1999.

[50] F. Dagrain, Etude des mecanismes de coupe des roches avec couteaux Uses - Approche des mécanismes de frottement sous les couteaux par le concept du troisième corps, Ph.D Thesis, Faculté Polytechnique de Mons, 2006.

[51] E. Detournay, T. Richard, M. Shepherd, Drilling response of drag bits: Theory and experiment, International Journal of Rock Mechanics and Mining Sciences 45 (2008) 1347-1360.

[52] L. F. Franca, Drilling action of roller-cone bits: modeling and experimental validation, Journal of Energy Resources Technology 132 (2010) 043101.

[53] A. Ghasemloonia, D. G. Rideout, S. D. Butt, A review of drillstring vibration modeling and suppression methods, Journal of Petroleum Science and Engineering 131 (2015) 150-164. 
[54] C. Germay, V. Denoel, E. Detournay, Multiple mode analysis of the selfexcited vibrations of rotary drilling systems, Journal of Sound and Vibration 325 (2009) 362-381.

[55] B. Besselink, N. van de Wouw, H. Nijmeijer, A semi-analytical study of stick-slip oscillations in drilling systems, Journal of Computational and Nonlinear Dynamics 6 (2011).

[56] H. Qiu, J. Yang, S. Butt, J. Zhong, Investigation on random vibration of a drillstring, Journal of Sound and Vibration 406 (2017) $74-88$.

[57] F. Real, A. Batou, T. Ritto, C. Desceliers, R. Aguiar, Hysteretic bit/rock interaction model to analyze the torsional dynamics of a drill string, Mechanical Systems and Signal Processing 111 (2018) 222-233.

[58] T. Ritto, M. Escalante, R. Sampaio, M. B. Rosales, Drill-string horizontal dynamics with uncertainty on the frictional force, Journal of Sound and Vibration 332 (2013) 145-153.

[59] D. Lobo, T. Ritto, D. Castello, Stochastic analysis of torsional drill-string vibrations considering the passage from a soft to a harder rock layer, Journal of the Brazilian Society of Mechanical Sciences and Engineering 39 (2017) 2341-2349.

[60] A. Depouhon, E. Detournay, Instability regimes and self-excited vibrations in deep drilling systems, Journal of Sound and Vibration 333 (2014) 2019 2039.

[61] Y. Khulief, F. Al-Sulaiman, S. Bashmal, Vibration analysis of drillstrings with self-excited stick-slip oscillations, Journal of sound and vibration 299 (2007) 540-558.

[62] T. Ritto, R. Aguiar, S. Hbaieb, Validation of a drill string dynamical model and torsional stability, Meccanica 52 (2017) 2959-2967. 
[63] A. Ersoy, M. D. Waller, Wear characteristics of PDC pin and hybrid core bits in rock drilling, Wear 188 (1995) 150-165.

[64] D. H. Zijsling, Rotary drill bit with cutting elements having a thin abrasive front layer, 1986. US Patent 4,607,711.

[65] D. A. Glowka, Design considerations for a hard-rock PDC drill bit, Technical Report, Sandia National Labs., Albuquerque, NM (USA), 1985.

[66] T. Richard, C. Coudyzer, S. Desmette, Influence of groove geometry and cutter inclination in rock cutting, 44th US Rock Mechanics Symposium and 5th US-Canada Rock Mechanics Symposium, American Rock Mechanics Association, 2010.

[67] T. Richard, Personal communications, 2016. 


\section{Appendix A. Results of cutting tests-Tuffeau}

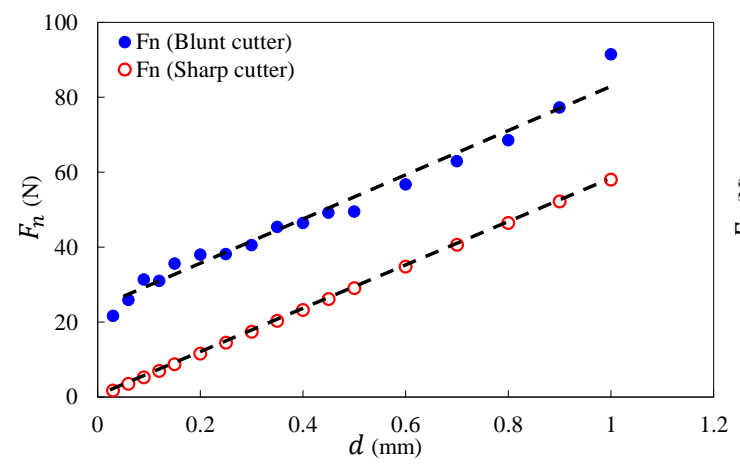

(a) $\beta=0.64^{\circ}, \theta=17.80^{\circ}$

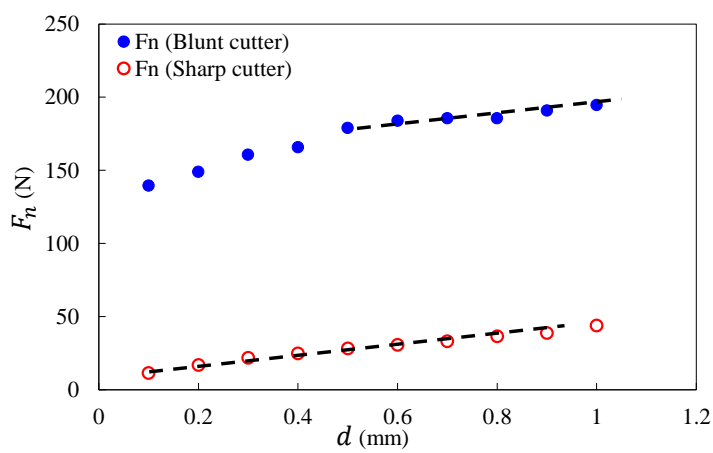

(c) $\beta=3.58^{\circ}, \theta=14.86^{\circ}$

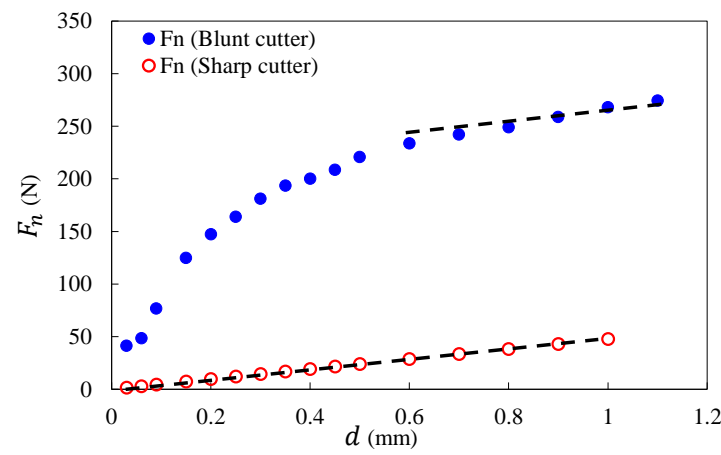

(e) $\beta=9.40^{\circ}, \theta=9.04^{\circ}$

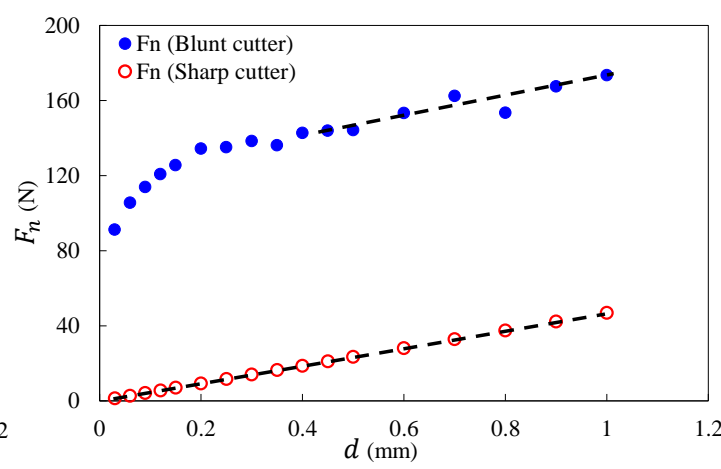

(b) $\beta=1.94^{\circ}, \theta=16.50^{\circ}$

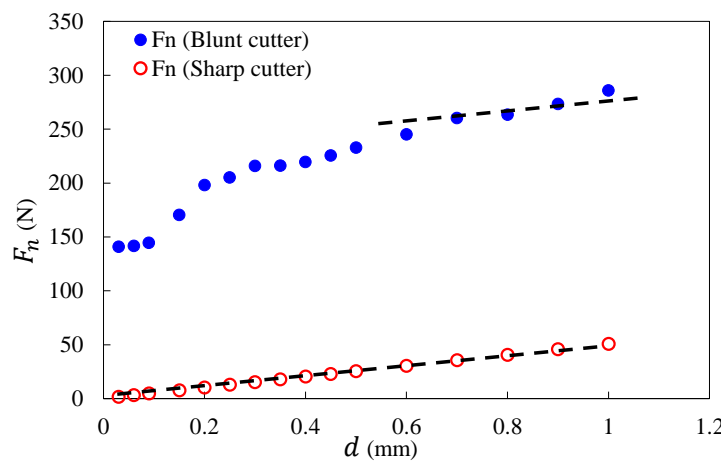

(d) $\beta=5.40^{\circ}, \theta=13.04^{\circ}$

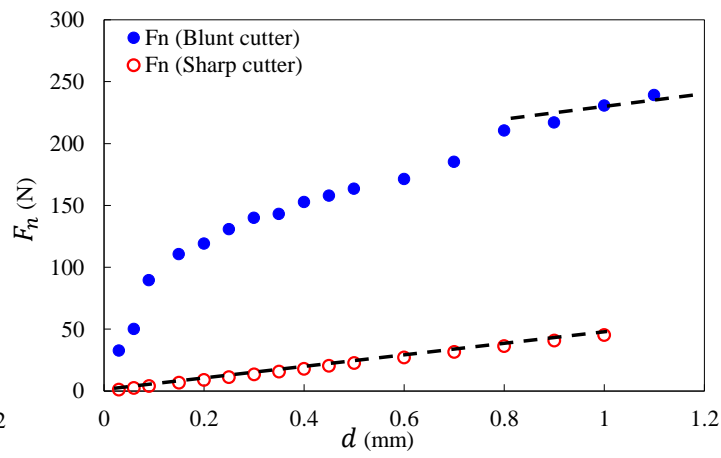

(f) $\beta=14.90^{\circ}, \theta=3.54^{\circ}$

Figure A.1: Evidence of $d_{*}$ with increase of inclination angle $(\beta)$. Tests conducted on Tuffeau limestone. 


\section{${ }_{a 5}$ Appendix B. Evolution of $d_{*}$ as a function of in- clination angle $(\beta)$}

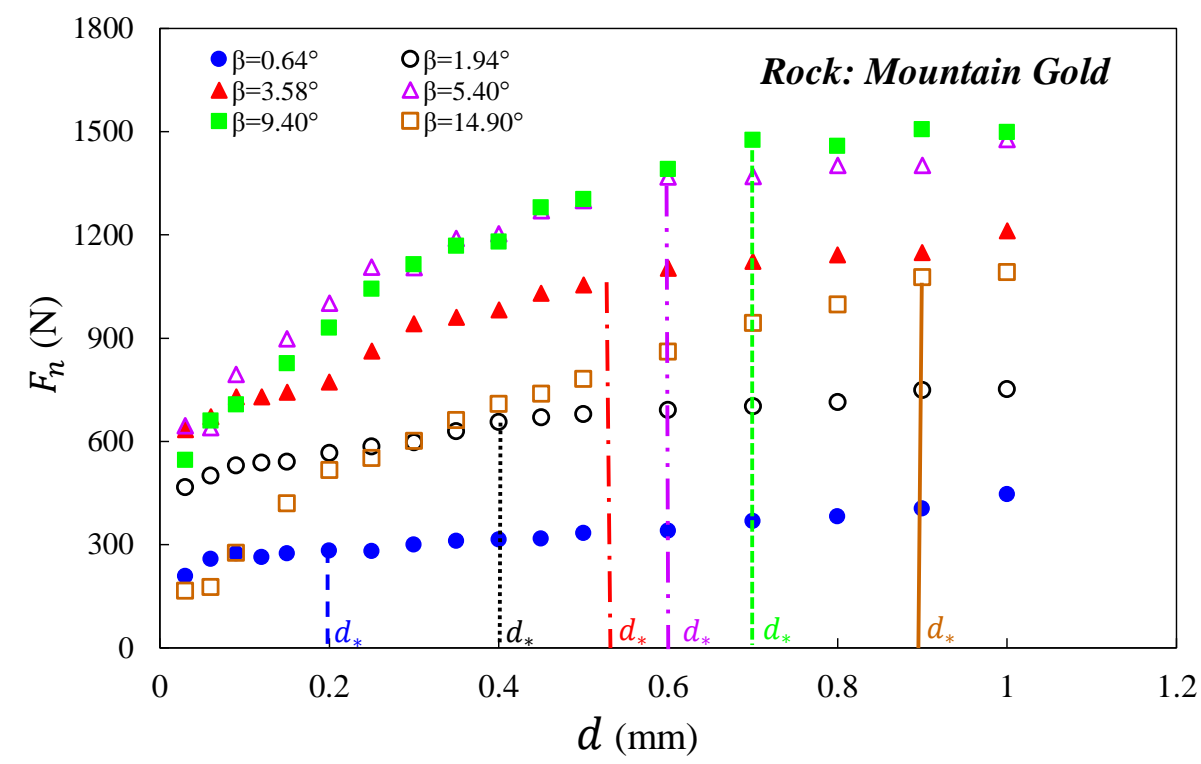

Figure B.1: Plot of normal force $\left(F_{n}\right)$ as a function of depth of cut for different inclination angles $(\beta)$. Tests carried out on Mountain Gold sandstone. 


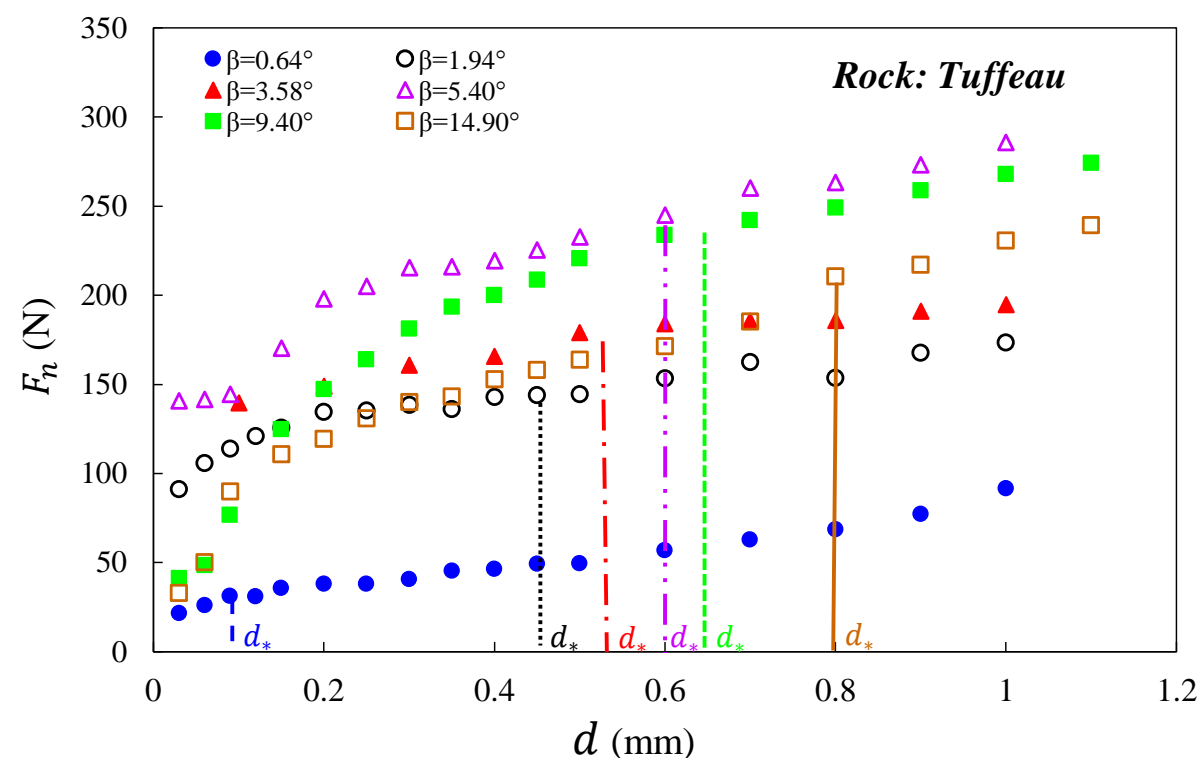

Figure B.2: Plot of normal force $\left(F_{n}\right)$ as a function of depth of cut for different inclination angles $(\beta)$. Tests carried out on Tuffeau limestone. 